\title{
Somatic mutations in the human brain: implications for psychiatric research
}

\author{
Masaki Nishioka ${ }^{1} \cdot$ Miki Bundo ${ }^{2,3} \cdot$ Kazuya Iwamoto $\mathbb{1}^{2} \cdot$ Tadafumi Kato $\mathbb{1}^{4}$ \\ Received: 21 November 2017 / Revised: 27 March 2018 / Accepted: 25 May 2018 / Published online: 7 August 2018 \\ (c) The Author(s) 2018. This article is published with open access
}

\begin{abstract}
Psychiatric disorders such as schizophrenia and bipolar disorder are caused by complex gene-environment interactions. While recent advances in genomic technologies have enabled the identification of several risk variants for psychiatric conditions, including single-nucleotide variants and copy-number variations, these factors can explain only a portion of the liability to these disorders. Although non-inherited factors had previously been attributed to environmental causes, recent genomic analyses have demonstrated that de novo mutations are among the main non-inherited risk factors for several psychiatric conditions. Somatic mutations in the brain may also explain how stochastic developmental events and environmental insults confer risk for a psychiatric disorder following fertilization. Here, we review evidence regarding somatic mutations in the brains of individuals with and without neuropsychiatric diseases. We further discuss the potential biological mechanisms underlying somatic mutations in the brain as well as the technical issues associated with the detection of somatic mutations in psychiatric research.
\end{abstract}

\section{Somatic mutation as a candidate mechanism for psychiatric disorders}

Advancements in genetic technologies such as microarray analysis and massively parallel sequencing have enabled us to analyze genetic information at a genome-wide level. Several of these genetic studies have identified candidate risk genes for a variety of psychiatric disorders. For example, a large-scale genome-wide association study

Electronic supplementary material The online version of this article (https://doi.org/10.1038/s41380-018-0129-y) contains supplementary material, which is available to authorized users.

Kazuya Iwamoto

iwamotok@kumamoto-u.ac.jp

$\bowtie$ Tadafumi Kato

kato@brain.riken.jp

1 Division for Counseling and Support, The University of Tokyo, Tokyo, Japan

2 Department of Molecular Brain Science, Graduate School of Medical Sciences, Kumamoto University, Kumamoto, Japan

3 PRESTO, Japan Science and Technology Agency, Saitama, Japan

4 Laboratory for Molecular Dynamics of Mental Disorders, RIKEN Brain Science Institute, Saitama, Japan
(GWAS) identified 108 genomic loci associated with schizophrenia using single-nucleotide polymorphism (SNP) microarray technology [1]. Additional studies have identified several copy-number variations (CNVs) associated with either schizophrenia [2-4] or autism spectrum disorder (ASD) [5]. Despite extensive genetic investigation, the SNPs and CNVs identified to date can only partially explain the liability to psychiatric disorders [6]. Even the 108 significant loci and $8 \mathrm{CNV}$ s identified in the aforementioned large-scale studies can explain only $3.4 \%$ and $0.85 \%$ of the variance in liability to schizophrenia, respectively [1,7]. The contribution of genomic features to ASD is greater than that to schizophrenia, with $6.02 \%$ of patients with ASD exhibiting known rare variants [8]. Even after considering the contribution of rare mutations, the total liability to these disorders cannot be explained.

Although the remaining liability to psychiatric disorders has classically been attributed to environmental factors, recent psychiatric research has focused on the role of de novo mutations, which represent a type of non-inherited genetic factor. De novo mutations occur prior to fertilization, before or during spermatogenesis/oocytogenesis (Fig. 1a). Some de novo mutations occurring before spermatogenesis/oocytogenesis are derived from genomic chimerism in either parent, which can be detected in a part of 
a)

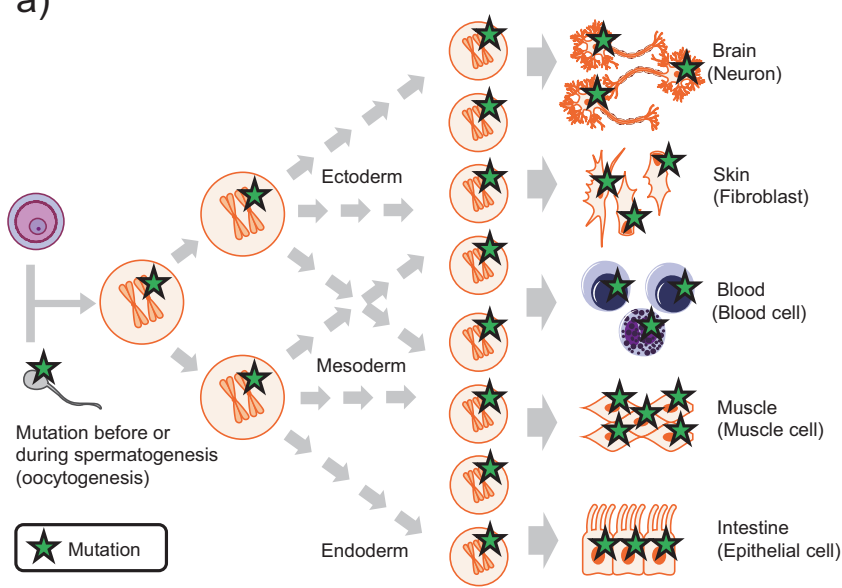

b)

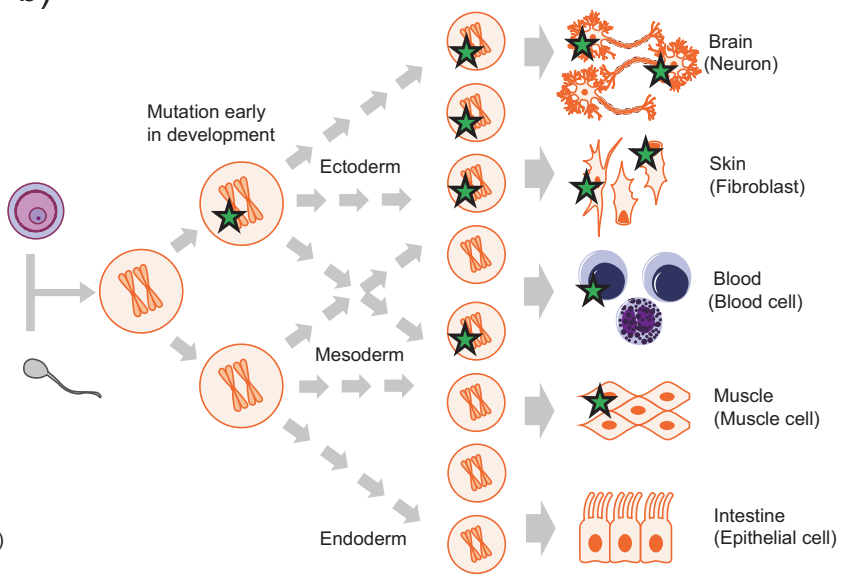

c)

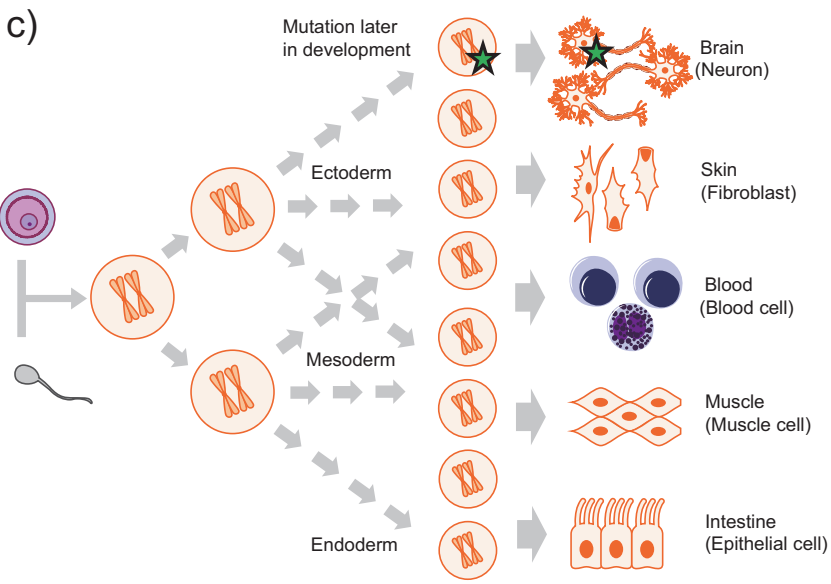

Fig. 1 De novo or somatic mutations and developmental stage. a De novo mutations occur before or during spermatogenesis/oocytogenesis. Mutations in the sperm or oocytes descend to the fertilized egg and are shared among all tissues in the proband. The descendants of the proband will inherit this de novo germline mutation with a probability of $50 \%$. b Somatic mutation occurring early in development, before the differentiation of somatic tissues. Mutations occurring early in development are shared among various tissues, but not all somatic cells or tissues, in the proband. The mutation exists in limited tissues or limited parts of each tissue. The descendants of the proband have a possibility of inheriting the somatic mutation, but with probability of $<50 \%$. c Somatic mutation occurring later in development, after the differentiation of somatic tissues. Mutations occurring after tissue differentiation are limited to a part of one tissue (brain, in this

the somatic tissues of the parent [9-12]. In contrast, de novo mutations occurring during spermatogenesis/oocytogenesis cannot be detected in the tissues of the parents, except for in a limited number of germ cells. Trio analyses have revealed that de novo mutations in SETDIA, CHD8, and other critical variants are associated with an increased risk of multiple psychiatric disorders [13-17]. Large case-control studies have validated these findings regarding SETD1A and CHD8 in patients with schizophrenia and ASD, respectively $[18,19]$. d)

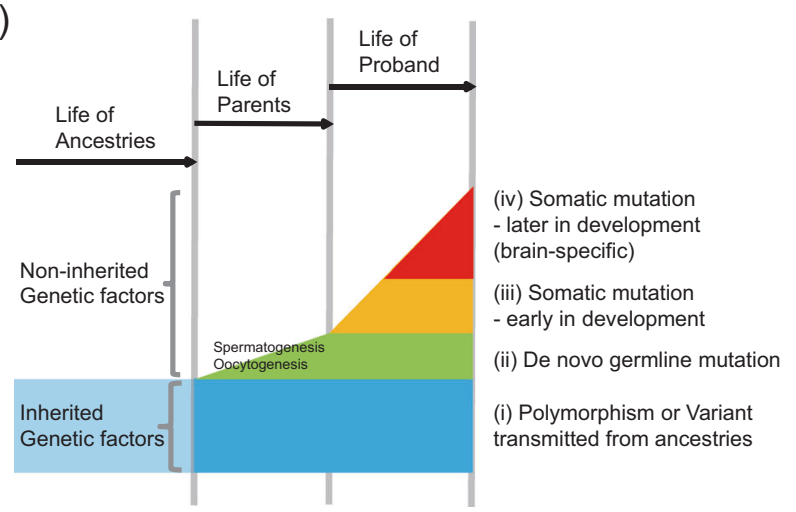

example) in the proband. The allele fraction of this type of somatic mutation is usually lower than that of somatic mutations occurring earlier. If the mutation is limited to the brain, the descendants of the proband will not inherit the somatic mutation. d A multi-layered scheme of genetic variants in a proband. (i) polymorphisms and variants transmitted from ancestries, (ii) de novo germline mutations, (iii) somatic mutations occurring early in development, and (iv) somatic mutations occurring later in development (brain-specific) from the viewpoint of a proband are illustrated with a time-axis. The polymorphisms and variants transmitted from ancestries are inherited genetic factors, but the other three mutation types are non-inherited genetic factors. These four types of germline or somatic variants (mutations) would have an additive effect on the individual phenotype. Somatic mutations (iii and iv) are the main focus of this review

In addition to germline de novo mutations, somatic or postzygotic mutations may occur following fertilization. Following such mutations, the genome in each somatic cell is not completely identical in one individual. Somatic mutations have also been well characterized as a pathological mechanism associated with cancer [20], and as an adaptive physiological mechanism associated with somatic rearrangement of immunoglobulin genes [21]. Cancers are caused by somatic mutations in key-driver genes in a specific tissue, and numerous additional somatic mutations may 
Fig. 2 Somatic mutation model explaining phenotypic differences between monozygotic (MZ) twins. MZ twins have identical genomes at the time of fertilization, but somatic mutation profiles diverge after fertilization. Somatic mutations during development may underlie phenotypic differences between the twins, including discordant risk for psychiatric disorders. In this illustrated model, MZ1 has somatic mutations in the relevant genes in development, which are shared between the neurons and blood cells, and has a psychiatric diagnosis. MZ2 has no somatic mutations in the relevant genes does not have a psychiatric diagnosis

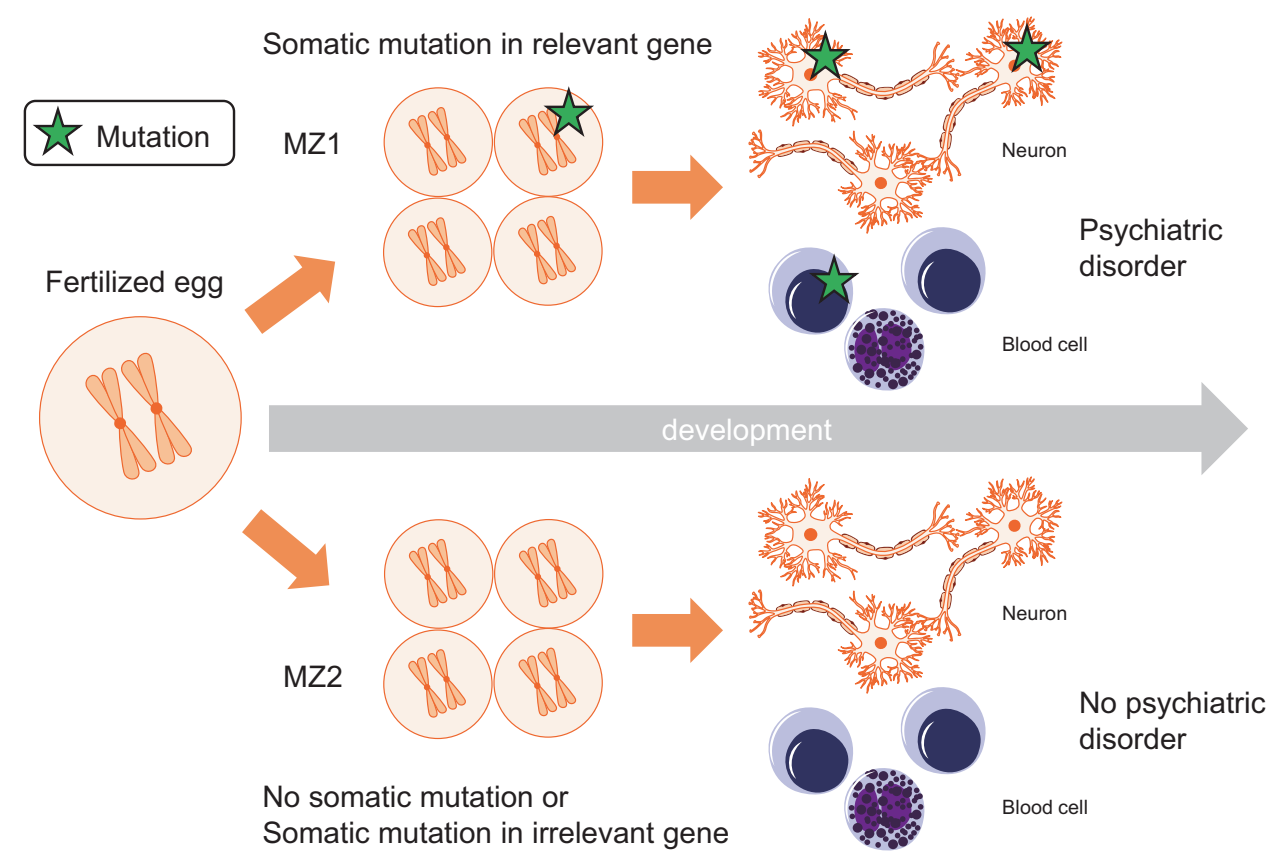

No somatic mutation or Somatic mutation in irrelevant gene accrue with advancement. In addition to cancerous tissues, recent genomic studies have systematically identified somatic mutations at the genome-scale in non-cancerous human tissues [22-26]. Furthermore, some mutations originally labeled as germline de novo mutations have subsequently been identified as somatic mutations that occurred after fertilization in the children [27], or prior to spermatogenesis/oocytogenesis in the parents [9].

Several human diseases are known to result from somatic mutations [28], and accumulating evidence indicates that somatic mutations may explain in part the liability to psychiatric disorders [29-32]. Such mutations can be observed in various tissues during the early developmental period, including peripheral tissues (e.g., blood cells) as well as brain cells (Fig. 1b). In contrast, somatic mutations that occur following differentiation exist within a limited region of a single tissue type (e.g., brain), and thus can be detected only in that tissue (Fig. 1c). Somatic mutations occur due to environmental insults, including inflammation and oxidative stress (described below), as well as stochastic changes during development.

While polymorphisms and the variants transmitted from ancestries are inherited genetic factors, the other three mutation types of de novo and somatic mutations illustrated in Fig. 1a-c are non-inherited genetic factors. Nonetheless, these all four types of germline and somatic variants (mutations) likely have an additive effect on the individual phenotype (Fig. 1d). For example, research has indicated that germline de novo mutations and inherited variants additively contribute to the risk for ASD [33, 34]. In principle, mutations resulting in embryonic lethality or severe congenital diseases cannot exist in the germline genome, although they may exist as somatic mutations, possibly resulting in relatively less severe physiological consequences. Previous studies regarding epileptic encephalopathy have revealed that single somatic mutations of PCDH19 result in less severe pathology than de novo mutations of the same gene [35, 36].

Polymorphisms and the variants transmitted from ancestries and de novo mutations, shared between monozygotic twins, contribute to the heritability estimated from studies of twins [37]. However, somatic mutations not shared between monozygotic twins do not directly contribute to the heritability, but affect the liability to psychiatric disorders in patients, by altering biological pathways similar to those affected by the germline mutations (Fig. 2). somatic mutations may contribute to a part of the total variation in liability that has been classically considered as being related to environmental factors.

The estimated rate of de novo mutations is $1-1.5 \times 10^{-8}$ per nucleotide per generation [10, 38, 39]. Somatic mutations may be more common than de novo mutations. Assuming a conservative estimate of 2.8 substitution mutations per cell per cell division [24] and symmetrical divisions in development, 86 billion neurons [40] would have gone through at least 36 divisions, thus resulting in a minimum of 100 single-nucleotide variants (SNVs) in one neuron. In fact, neurons likely undergo many more cell divisions, and mutation within neural tissues occurs via mechanisms other than replication errors during cell division (described below). In addition, other types of mutations (e.g., structural variants) may occur, increasing the number of mutational events beyond this minimum estimation. 
Table 1 Genomic analysis of somatic mutations in the brains of individuals without neuropsychiatric diseases

\begin{tabular}{|c|c|c|c|}
\hline Mutation type & Brain region & Cell type & References \\
\hline \multirow[t]{8}{*}{ SNV } & Frontal cortex & Single neuron & Lodato et al. [44] \\
\hline & Fetal frontal cortex & Clonally cultured single cell & Bae et al. [43] \\
\hline & Fetal parietal cortex & Clonally cultured single cell & Bae et al. [43] \\
\hline & Fetal basal ganglia & Clonally cultured single cell & Bae et al. [43] \\
\hline & Prefrontal cortex & Single neuron & Lodato et al. [45] \\
\hline & Hippocampus & Single neuron & Lodato et al. [45] \\
\hline & Frontal cortex & Bulk & Nishioka et al. [52] \\
\hline & Cerebellum & Bulk & Nishioka et al. [52] \\
\hline \multirow[t]{2}{*}{$\mathrm{CNV}$} & Frontal cortex & $\begin{array}{l}\text { Single neuron } \\
\text { Single iPS-derived neuron } \\
\text { Single iPS-derived neural precursor } \\
\text { cell }\end{array}$ & McConnell et al. [53] \\
\hline & Frontal cortex & Single neuron & Cai et al. [54] \\
\hline \multirow[t]{2}{*}{ MEI (LINE-1, Alu) } & Hippocampus & Bulk & Baillie et al. [65] \\
\hline & Caudate nucleus & Bulk & Baillie et al. [65] \\
\hline \multirow[t]{5}{*}{ MEI (LINE-1) } & Frontal cortex & Single neuron & Evrony et al. [68] \\
\hline & Caudate nucleus & Single neuron & Evrony et al. [68] \\
\hline & Frontal cortex & Single neuron & Evrony et al. [69] \\
\hline & Hippocampus & $\begin{array}{l}\text { Single neuron } \\
\text { Single glia }\end{array}$ & Upton et al. [66] \\
\hline & Caudate nucleus & $\begin{array}{l}\text { Single neuron } \\
\text { Single glia }\end{array}$ & Upton et al. [66] \\
\hline \multirow[t]{4}{*}{ Aneupoloidy } & Frontal lobe & Single neuron & Knouse et al. [56] \\
\hline & Frontal cortex & Single neuron & van den Bos et al. [12 \\
\hline & Cortex & $\begin{array}{l}\text { Neuron (FISH) } \\
\text { Non-neuron (FISH) }\end{array}$ & Rehen et al. [55] \\
\hline & Hippocampus & $\begin{array}{l}\text { Neuron }(\text { FISH) } \\
\text { Non-neuron (FISH) }\end{array}$ & Rehen et al. [55] \\
\hline
\end{tabular}

SNV single-nucleotide variant, $C N V$ copy-number variation, $M E I$ mobile element insertion, LINE-1 long interspersed nuclear element-1, FISH fluorescence in situ hybridization
Previous research groups have published excellent reviews that organize recent knowledge regarding somatic mutation in the human brain from a neurological/neuroscientific perspective [30-32]. In the present report, we review recent evidence regarding somatic mutations in the human brain focusing on the implications of these findings for psychiatry as well as technical issues associated with genomic analysis. We begin by comparing somatic mutations in the brains of individuals without neuropsychiatric diseases (Table 1) to those in individuals with neuropsychiatric diseases (Table 2). We then discuss the potential biological mechanisms underlying somatic mutations in the brain, as well as technical issues for future psychiatric research. Although somatic mutations in mitochondria also have a critical role in psychiatric disorders, those studies were reviewed elsewhere [41, 42], and thus we have focused on somatic mutations in genomic DNA.

\section{Somatic mutations in the brains of individuals without neuropsychiatric diseases}

\section{SNVs}

One neuronal progenitor cell in the fetal cortex has 200-400 somatic SNVs [43], while one mature neuron in the adult cortex has $\sim 1000-2500$ somatic SNVs [44, 45]. These estimations are based on whole-genome sequencing (WGS) of single-cell genomes after clonal cell proliferation or whole-genome amplification (WGA). SNVs in a single neuron in the prefrontal cortex and dentate gyrus increase by $\sim 23$ and $\sim 40$ per year, respectively [45]. The accumulation rate in dentate gyrus neurons is twofold higher than that in neurons of the prefrontal cortex, probably owing to the difference in the rate of neurogenesis. Some mutations in single neurons are also detected in other brain regions with various allele fractions $[43,44]$. The allele fractions in 
Table 2 Somatic mutations in patients with neuropsychiatric diseases

\begin{tabular}{|c|c|c|c|c|}
\hline Disease/disorder & Implicated gene & Mutation type & Sample & References \\
\hline \multicolumn{5}{|l|}{ Postmortem brain } \\
\hline \multirow[t]{2}{*}{ Hemimegalencephaly } & PIK3CA, AKT3, MTOR & SNV & The affected brain region & $\begin{array}{l}\text { Poduri et al. [95] } \\
\text { Lee et al. [92] } \\
\text { D'Gama et al. [93] } \\
\text { Jansen et al. [94] }\end{array}$ \\
\hline & 1q trisomy/tetrasomy & $\mathrm{CNV}$ & The affected brain region & $\begin{array}{l}\text { Poduri et al. [95] } \\
\text { Cai et al. [54] }\end{array}$ \\
\hline Cortical dysplasia type II & MTOR & SNV & The affected brain region & $\begin{array}{l}\text { Lim et al. [97] } \\
\text { Nakashima et al. [98] } \\
\text { Mirzaa et al. [96] }\end{array}$ \\
\hline Sturge-Weber syndrome & GNAQ & SNV & Brain & $\begin{array}{l}\text { Shirley et al. [99] } \\
\text { Nakashima et al. [100] }\end{array}$ \\
\hline \multirow[t]{2}{*}{ Huntington's disease } & HD & CAG repeat & Striatum & Kennedy et al. [103] \\
\hline & HD & CAG repeat & $\begin{array}{l}\text { Frontal cortex } \\
\text { Cerebellum }\end{array}$ & Swami et al. [104] \\
\hline Rett syndrome & LINE1 copy number & MEI & iPS-derived NPC & Muotri et al. [114] \\
\hline Ataxia telangiectasia & LINE1 copy number & MEI & $\begin{array}{l}\text { Hippocampal neuronal } \\
\text { nuclei }\end{array}$ & Coufal et al. [113] \\
\hline Cockayne syndrome & Global SNV increase & SNV & Prefrontal cortex neuron & Lodato et al. [45] \\
\hline Xeroderma pigmentosum & Global SNV increase & SNV & Prefrontal cortex neuron & Lodato et al. [45] \\
\hline \multirow[t]{7}{*}{ Alzheimer's disease } & PSEN1 & SNV & Cerebral cortex & Beck et al. [118] \\
\hline & MAPT, PSEN2 & SNV & Entorhinal cortex & Sala Frigerio et al. [116] \\
\hline & Many (not validated) & SNV & Hippocampus & Parcerisas et al. [119] \\
\hline & APP copy-number increase & $\mathrm{CNV}$ & $\begin{array}{l}\text { Prefrontal cortex } \\
\text { Cerebellum }\end{array}$ & Bushman et al. [117] \\
\hline & No different aneuploidy & Aneuploidy & Frontal cortex & van den Bos et al. [121] \\
\hline & Chromosome 21 loss/gain & Aneuploidy & Cerebral cortex & \\
\hline & Excess aneuploidy & Aneuploidy & $\begin{array}{l}\text { Entorhinal cortex } \\
\text { Occipital cortex }\end{array}$ & \\
\hline Autism spectrum disorder & CACNA1C, SCN1A, SETD2 & SNV & $\begin{array}{l}\text { Prefrontal cortex } \\
\text { Cerebellum }\end{array}$ & D’Gama et al. [115] \\
\hline \multirow[t]{5}{*}{ Schizophrenia } & LINE-1 copy number & MEI & $\begin{array}{l}\text { Cortex neuronal nuclei } \\
\text { Cortex non-neuronal } \\
\text { nuclei } \\
\text { iPS-derived neurons }\end{array}$ & Bundo et al. [89] \\
\hline & LINE-1 copy number & MEI & $\begin{array}{l}\text { Dorsolateral prefrontal } \\
\text { cortex }\end{array}$ & Doyle et al. [112] \\
\hline & Deletions in PRKRA and others & $\mathrm{CNV}$ & $\begin{array}{l}\text { Prefrontal cortex } \\
\text { Cerebellum }\end{array}$ & Kim et al. [108] \\
\hline & $1 \mathrm{p} 36.21,1 \mathrm{p} 13.3$ & $\mathrm{CNV}$ & Striatum & Sakai et al. [109] \\
\hline & Chromosome 1 loss/gain & Aneuploidy & $\begin{array}{l}\text { Cortex (Brodmann area } \\
\text { 10) }\end{array}$ & Yurov et al. [110] \\
\hline \multicolumn{5}{|l|}{ Peripheral tissues } \\
\hline Hemimegalencephaly & PIK3CA & SNV & $\begin{array}{l}\text { Blood } \\
\text { Saliva } \\
\text { Buccal swab }\end{array}$ & Riviere et al. [105] \\
\hline Megalencephaly & PIK3CA & SNV & Blood & Mirzaa et al. [96] \\
\hline Double cortex syndrome & DCX, LIS1 & SNV & Blood & Jamuar et al. [106] \\
\hline $\begin{array}{l}\text { Periventricular nodular } \\
\text { heterotopia }\end{array}$ & FLNA & SNV & Blood & Jamuar et al. [106] \\
\hline Pachygyria & TUBB2B & SNV & Blood & Jamuar et al. [106] \\
\hline
\end{tabular}


Table 2 (continued)

\begin{tabular}{|c|c|c|c|c|}
\hline Disease/disorder & Implicated gene & Mutation type & Sample & References \\
\hline Rett syndrome & MECP2 & Small deletion & $\begin{array}{l}\text { Peripheral blood } \\
\text { lymphocytes }\end{array}$ & $\begin{array}{l}\text { Clayton-Smith et al. } \\
{[125]}\end{array}$ \\
\hline \multirow[t]{4}{*}{ Autism spectrum disorder } & $\begin{array}{l}\text { KMT2C, NCKAP1, MYH10, and } \\
\text { others }\end{array}$ & SNV & Blood & Freed et al. [122] \\
\hline & $\begin{array}{l}\text { MFRP,MYO9B, PTK7, TANC2, } \\
\text { MEGF11, and others }\end{array}$ & SNV & Blood & Dou et al. [11] \\
\hline & $\begin{array}{l}\text { KLF16, MSANTD2, SCN2A, } \\
\text { HNRNPU, SMARCA4, and others }\end{array}$ & SNV & Blood & Lim et al. [123] \\
\hline & $\begin{array}{l}\text { CHD2, CTNNB1, KMT2C, } \\
\text { SYNGAP1, RELN, and others }\end{array}$ & SNV & Blood & Krupp et al. [12] \\
\hline \multicolumn{5}{|l|}{ Monozytotic twin } \\
\hline Darier disease & ATP2A2 & Small deletion & Blood (MZ) & Sakuntabhai et al. [130] \\
\hline Van der Woude syndrome & IRF6 & SNV & Blood (MZ) & Kondo et al. [131] \\
\hline Dravet syndrome & SCN1A & SNV & $\begin{array}{l}\text { Lymphocytes (MZ) } \\
\text { Hair-follicle cells (MZ) } \\
\text { Cheek cells (MZ) } \\
\text { Fibroblasts (MZ) } \\
\text { Olfactory neuroepithelium } \\
\text { (MZ) }\end{array}$ & Vadlamudi et al. [132] \\
\hline Neurofibromatosis type 1 & NF1 & $\mathrm{SNV}$ & $\begin{array}{l}\text { Blood (MZ) } \\
\text { Buccal swab (MZ) } \\
\text { Urine (MZ) }\end{array}$ & Vogt et al. [133] \\
\hline Parkinson-related diseases & 31 loci & $\mathrm{CNV}$ & Blood (MZ) & Bruder et al. [136] \\
\hline Fragile X syndrome (severity) & FMR1 & CGG repeat & Blood (MZ) & $\begin{array}{l}\text { Helderman-van den } \\
\text { Enden et al. [135] }\end{array}$ \\
\hline Gender dysphoria & FBXO38, SMOC2, TDRP & SNV & Blood lymphocytes (MZ) & Morimoto et al. [134] \\
\hline Delusional disorder & ABCC9 & SNV & Blood (MZ) & Nishioka et al. [137] \\
\hline
\end{tabular}

Note that relevancy of the implicated genes to each disease/disorder differs among the listed studies

$S N V$ single-nucleotide variant, $C N V$ copy-number variation, $M E I$ mobile element insertion, LINE-1 long interspersed nuclear element-1, FISH fluorescence in situ hybridization

certain brain regions are postulated to be correlated with the time point of mutation occurrence, such that larger allele fractions may reflect mutation during the earlier stages of development. Bae et al. [43] provided an estimation of 5.1 SNVs/day/single progenitor cell during neurogenesis, 8.6 $\mathrm{SNVs}$ /division/progenitor cell, and 1.3 SNVs/division/ daughter cell in the early human embryo. Neurogenesis is associated with a higher mutation rate than early embryogenesis, although frequency of adult neurogenesis in the human brain is under active discussion [46].

The cytosine $(\mathrm{C})$ to thymine $(\mathrm{T})$ transition is a prominent mutation type in neuronal somatic SNVs [43-45]. The frequency of approximately $80 \%$ of $\mathrm{C}>\mathrm{T}$ [44] is higher than the frequency observed in germline mutations [10, 47], although a part of the detected $\mathrm{C}>\mathrm{T}$ may be derived from experimental artifacts [48]. The $\mathrm{C}>\mathrm{T}$ transition is enriched at 5-methylated cytosines $(5 \mathrm{mC})$ in $\mathrm{CpG}$ and $\mathrm{CpH}$ dinucleotides, suggesting that these mutations are derived from DNA methylation/demethylation [44]. With aging, the $\mathrm{C}>\mathrm{T}$ fraction decreases, while the cytosine to adenine $(\mathrm{C}>\mathrm{A})$ and $\mathrm{T}>\mathrm{C}$ fractions increase in the cortex $[43,45]$. The dentate gyrus neuron is one exception, where the $\mathrm{C}>\mathrm{T}$ fraction increases with aging, probably due to neurogenesis [45]. The C $>\mathrm{A}$ transversion is probably induced by oxidative DNA damage (see below) [43, 45]. Lodato et al. [45] inferred that the $\mathrm{T}>\mathrm{C}$ increase is linked to fatty-acid oxidation DNA damage.

The observed somatic mutations were enriched in neurodevelopment-related genes and strands undergoing active transcription. The higher length of the neuronexpressed genes [49-51] may be a reason for mutational susceptibility. Somatic mutations in mature neurons likely occur during active transcription [44], while somatic mutations in fetal neurons are less abundant in the genomic regions with histone marks of fetal brains and embryonic stem cells [43]. The genomic regions susceptible to mutation may differ depending on the developmental stage. The bias of somatic mutations toward neurodevelopmental genes in mature neurons is indicative of their relevance to psychiatric disorders.

In a recent study, we explored somatic mutations in human brain tissue from three healthy individuals via WGS 
at a depth of $\sim 100 \times$. Allele fractions were assayed and validated via target amplicon sequencing (TAS), ranging from 0.5 to $14 \%$ in bulk tissue obtained from the cortex, cerebellum, and liver [52]. The somatic mutations exhibited considerable spatial diversity; some mutations were observed in the brain but not the liver, while others were observed in the cortex but not the cerebellum. In accordance with the findings of previous researchers, we also observed a greater frequency of somatic mutations and $\mathrm{C}>\mathrm{T}$ bias in neuron-expressed genes.

\section{CNVs and aneuploidy}

Somatic CNVs have also been reported at the single-cell level. McConnell et al. [53] assayed somatic CNVs in the genomes of individual neurons using low-depth WGS and microarray analysis following WGA with degenerate oligonucleotide-primed PCR (DOP-PCR). Forty-five of 110 (40.9\%) single neurons in the frontal cortex tissue from three healthy individuals exhibited somatic CNVs with lengths ranging from 2.9 to $75 \mathrm{Mb}$. In these somatic CNVs, deletions were more frequent than duplication. In a similar study, Cai et al. [54] assayed somatic CNVs in the genomes of individual neurons via low-depth WGS using two methods of WGA, multiple displacement amplification (MDA) with phi29 DNA polymerase and DOP-PCR. Five percent of 82 neurons from three healthy men exhibited aneuploidy (aberrant haploid sets). The authors estimated that the average single neuron had $3.4 \mathrm{CNV}$ s with an approximate size of $18 \mathrm{Mb}$ each. Neurons exhibited more deletions and single-cell-specific CNVs than lymphoblastoid cells, likely reflecting a low rate of proliferation in neurons. Notably, $98 \%$ of the neuronal CNVs were deletions, while only around $50 \%$ of CNVs in the lymphoblastoid cells were deletions in this study. Among the somatic CNVs identified was a $2.9 \mathrm{Mb}$ duplication at 15q13.2-13.3, which has been associated with schizophrenia [3] and ASD [5]. One interpretation is that 15q13.213.3 is vulnerable to copy-number alterations in neurons as well as germlines.

Several research groups have identified somatic aneuploidy in the human brain. Rehen et al. [55] reported that $4 \%$ of the neurons and glial cells exhibited somatic aneuploidy in contrast to $0.6 \%$ of the white blood cells. This estimation was based on microscopic observation following fluorescence in situ hybridization (FISH) analyses, which revealed that chromosomal deletion and duplication occurred at a ratio of $1: 1$, likely due to unbalanced separation of chromosomes during mitosis. Single-cell WGS (depth: $0.1 \times$ ) experiments by Knouse et al. [56] demonstrated that $2.2 \%$ of 89 neurons from the frontal lobes of four individuals without neuropsychiatric diseases exhibited aneuploidy. Based on the results of FISH and single-cell WGS analyses, the aneuploidy rate of neurons should be $2-4 \%$. Previous studies have identified tetra-ploidy in mouse pyramidal neurons of cortical layer 5 [57], encouraging future investigations of an equivalent phenomenon in human neurons.

\section{Mobile elements}

Mobile elements occupy $\sim 45 \%$ of the human genome [58]. Long interspersed nuclear element-1 (LINE-1) is one of the major mobile elements, exhibiting active transposition abilities and occupying $17 \%$ of the human genome. The LINE-1 sequence can proliferate in the human genome through the following processes called retrotransposition: (i) transcription of mRNA from an internal promoter; (ii) translation of LINE-1 mRNA, producing a LINE-1 RNAprotein complex with endonuclease and reverse transcriptase activity; (iii) reverse-transcription to DNA and concurrent insertion into the human genome [59]. Several heritable genetic diseases such as hemophilia [60] are known to result from germline LINE-1 retrotransposition [61]. The retrotransposition activity of LINE-1 is usually suppressed by epigenetic systems, including DNA methylation and histone modification. However, LINE-1 retrotransposition activity has been identified in the neuronal genome of both humans and mice [62-64].

The rate of somatic retrotransposition in the human brain is under active investigation. Baillie et al. [65] observed somatic retrotransposition of LINE-1 and Alu in bulk tissue obtained from the human hippocampus and caudate nucleus. Somatic retrotransposition was detected using retrotransposon capture sequencing (RC-Seq), in which retrotransposons in the genome were massively sequenced following capture. The insertion sites of retrotransposons were identified by flanking genomic sequences. The authors detected 13,700 and 7700 putative somatic retrotranspositions of LINE-1 and Alu, respectively, in three individuals. Insertion enrichment was also observed in exons and synapse-related genes. Applying RC-Seq to neurons and glia, Upton et al. [66] reported LINE-1 insertion sites in single cells, using WGA by multiple annealing and looping-based amplification cycles (MALBAC) [67]. After Sanger sequencing validation, they estimated that the average somatic LINE-1 insertions per single cell are $\sim 13.7$, 6.5, and 10.7 in hippocampal neurons, hippocampal glia, and cortical neurons, respectively. These estimations were calculated based on experiments involving 92 hippocampal neurons from four individuals, 22 hippocampal glia from three individuals, and 35 cortical neurons from three individuals.

Evrony et al. detected LINE-1 insertions in single neurons using two independent approaches after WGA of single-neuron genomes with MDA [68, 69]. The first 
approach, L1Hs-seq [70], was used to comprehensively amplify and massively sequence genomic regions around the $3^{\prime}$ end of L1Hs. LINE-1 insertion sites were determined based on the sequences adjacent to the L1Hs $3^{\prime}$ end [68]. Among the various LINE-1 subfamilies, L1Hs is the only group that exhibits retrotransposition activity in humans. The authors examined a total of 300 neurons from the frontal lobe and caudate nucleus of three healthy individuals. Sanger sequence validation suggested that $\sim 0.07$ new insertions per neuron occurred in this population. In the second approach, the authors performed bioinformatics analysis of WGS data obtained at a depth of $40 \times$ [69]. The sequence reads containing the LINE-1 sequence were extracted from the raw WGS data, and the insertion position of LINE1 was determined from the adjacent sequence. The second approach detected two somatic LINE-1 insertions in 16 single neurons obtained from one healthy man. The insertion sites and allele fractions of new insertions were validated and quantified using ddPCR, with allele fractions ranging from 0.04 to $1.7 \%$ in various brain regions.

As previously mentioned, estimates of new LINE-1 insertion in single neurons range from 0.07 to 13.7. Evrony et al. [71] reanalyzed the data of Upton et al., highlighting that most of the new somatic insertions reported were artifacts due to WGA. Stringent reanalysis of the data led them to estimate that the actual rate of new insertions was around 0.2 per single neuron. Thus, the rate of LINE-1 insertions in human neurons remains a subject of active discussion.

\section{Biological mechanisms underlying somatic mutations in the brain}

Somatic mutations associated with cancer are thought to derive primarily from cell proliferation [20]. As neural tissue exhibits little to no proliferative capacity, the mechanisms underlying somatic mutation in the brain should be different from those associated with cancer.

Previous research has indicated that $\mathrm{C}>\mathrm{T}$ transitions account for $\sim 80 \%$ of somatic SNVs in single neurons [44]. Although some of these $\mathrm{C}>\mathrm{T}$ transitions were likely derived from artificial $\mathrm{C}>\mathrm{U}$ deamination due to cell lysis during the preparation of single-cell samples [48], we also observed the same bias for $\mathrm{C}>\mathrm{T}$ transition following a WGS analysis of bulk brain tissues, which were free from deamination during cell lysis [52]. Neurons have a characteristic $5 \mathrm{mC}$ at non-CpG sites and a relatively greater amount of 5hydroxymethylcytosine $(5 \mathrm{hmC})$ than other tissues [72, 73]. Moreover, $5 \mathrm{hmC}$ is an intermediate product during active demethylation of $5 \mathrm{mC}$ to $\mathrm{C}$, and previous studies have suggested that this process, including base excision repair, is susceptible to mutation [74-76]. However, one study reported that $5 \mathrm{hmC}$ was associated with an $~ 53 \%$ decrease in the frequency of $\mathrm{C}>\mathrm{T}$ mutations at $\mathrm{CpG}$ sites when compared with $5 \mathrm{mC}$ [77]. It is also possible that AID/ APOBEC cause in vivo cytosine deamination of $\mathrm{mC}$ to $\mathrm{T}$ [78], although this process is reported to be chemically disfavored [79].

Neural activity induces double-stranded breaks in genomic DNA [80], and mutations can occur during the repair process. Several studies have suggested that these doublestranded breaks are enriched in genes associated with neural or synaptic activity [81, 82]. Double-stranded breaks represent one candidate mechanism underlying the development of somatic mutations in the human brain.

Although oxidative damage is not restricted to the brain, the brain accounts for $20 \%$ of all oxygen consumption in the human body, thus sustaining a greater amount of oxidative damage than other organs. Oxidative damage is estimated to cause $\sim 1000$ single-stranded breaks per cell per day [83]. Oxidative damage produces 8-oxoguanine, which occasionally incorporates adenine as an incorrect complementary base. If DNA repair systems fail to recover the original pair (guanine and cytosine), the incorrectly incorporated adenine incorporate thymine as a correct complementary base, resulting in $\mathrm{C}>\mathrm{A}$ transversions [84]. Research has revealed that oxidative damage is enriched in the promoter regions of genes associated with synaptic plasticity, vesicular transport, calcium signaling, and mitochondrial function, and that such damage reduces the expression of these genes [85]. Impaired mitochondrial function may also contribute to DNA damage by increasing reactive oxygen species or reducing the ATP available for DNA repair [86]. Oxidative damage to DNA in the human brain accumulates with age, particularly in the mitochondria [87], and has been shown to be associated with neurodegeneration [88].

The mechanism underlying retrotransposition in the human brain remains largely unknown. While epigenetic modification is assumed to suppress retrotransposon transcriptional activity [59], the mechanisms underlying retrotransposition in the human brain require further investigation [62-64]. Our data suggested that inflammatory stress during the fetal period causes somatic retrotransposition in a polyinosinic-polycytidylic acid (polyI:C) mouse model [89], suggesting that environmental factors lead to somatic retrotransposition, likely through neuroinflammation.

Retrotransposons or repeat sequences can induce nonhomologous recombination of DNA [59], resulting in genome instability and somatic CNVs during development. In addition, LINE-1 can induce deletion between LINE-1 regions via endonuclease activity even without transcription or new insertion [90]. One study suggested that circular DNA fragments with a length of 200-400 bp are enriched in the adult mouse brain, and that somatic microdeletions in 
brain genomes arise from the excision of small circular DNAs [91]. However, the mechanisms underlying the generation of somatic SNVs, CNVs, and retrotransposition remain to be fully elucidated.

\section{Somatic mutations in brain malformations and neurodegenerative disorders}

Several studies have identified somatic mutations in the known risk genes for certain brain malformations. In many cases, potential somatic mutations have been identified in brain regions exhibiting local anatomical changes.

Hemimegalencephaly refers to a disease in which one cerebral hemisphere grows to be larger than the other. Several studies utilizing whole-exome sequencing (WES) or TAS have observed somatic SNVs in PIK3CA, AKT3, or $M T O R$ in the overgrown brain region (dissected during surgical treatment) [92-96]. Lee et al. [92] reported somatic mutations with allele fractions of $8-40 \%$ in the affected regions of 6 out of 20 patients with hemimegalencephaly following mass spectrometry analysis. Other groups have reported an allele fraction within a similar range or higher [93-95]. Single-cell CNV analysis revealed 1q tetrasomy in $20 \%$ of 76 single cells (46 neurons and 30 non-neurons) obtained from the affected brain region of one patient with hemimegalencephaly [54]. The same group observed somatic 1q trisomy in two other patients with hemimegalencephaly [95]. Considering that AKT3 is on 1q, these findings indicate that somatic CNVs of 1q may also cause hemimegalencephaly.

Cortical dysplasia with epilepsy is another example of a brain malformation caused by somatic mutations [96-98]. Lim et al. [97] identified somatic mutations in MTOR in the affected brain region of patients with cortical dysplasia type II and epilepsy. They detected putative somatic mutations using WES at a depth of 400-700×, validating and quantifying the candidate mutation via TAS. Twelve of 77 patients had somatic mutations in MTOR with allele fractions of 1.3 to $12.6 \%$ in the affected regions. Additional experiments in model mice demonstrated the causality from MTOR somatic mutation to epilepsy, as well as the efficacy of rapamycin for the treatment of epilepsy in such cases. Nakashima et al. [98] detected somatic SNVs in MTOR in the affected brain regions of six out of 13 patients with cortical dysplasia type IIb. Somatic SNVs were detected via WES and TAS, and allele fractions of somatic SNVs in MTOR were determined as 1.54 to $9.31 \%$ or 1.45 to $5.51 \%$ via TAS or ddPCR, respectively. The associations between somatic mutation in the relevant genes and hemimegalencephaly/cortical dysplasia have been independently reported by several groups and are thus considered reliable.
Somatic mutations in GNAQ (c.548G>A, p.Arg183Glu) have been reported in patients with Sturge-Weber syndrome (a rare congenital neurological disorder characterized by seizures, mental retardation, cerebral malformations, and other symptoms). Shirley et al. [99] reported an allele fraction of $\sim 11.15 \%$ in the brains of 15 of the 18 recruited patients, while Nakashima et al. [100] reported an allele fraction of approximately $8.94 \%$ in the brains of 12 of the 15 recruited patients.

Triplet repeat expansion is thought to be a causative mutation for several neurodegenerative diseases such as Huntington's disease and fragile X syndrome [101]. Triplet repeats are unstable in somatic cells, including those of the brain [102]. Somatic triplet repeat expansion has been identified in the brains of patients with Huntington's disease [103], particularly in brain regions with aggressive neurodegeneration, and has been correlated with disease onset at an early age [104]. Patients with Cockayan syndrome and Xeroderma pigmentosum, genetic disorders with neurological symptoms caused by defects in the DNA damage repair system, have a 2.5 -fold higher rate of neuronal somatic mutations than healthy individuals [46]. C>A transitions are characteristic of these patients, indicating oxidative DNA damage.

Intriguingly, somatic mutations in the relevant genes have been identified not only in the affected brain regions, but also in peripheral tissues. Somatic mutations in PIK3CA were observed in the blood or saliva samples from 10 patients with hemimegalencephaly, with allele fractions ranging from 1 to $43 \%$ when examined via TAS [105]. Somatic SNVs in blood cells have also been observed in patients with other severe brain malformations such as double cortex syndrome, periventricular nodular heterotopia, and pachygyria. Jamuar et al. [106] selected the known risk genes for these brain malformations and performed TAS on the blood samples obtained from 158 patients. Eight of these 158 patients exhibited somatic SNVs in DCX, LIS1, TUBB2B, or FLNA. The allele fraction ranged from 5 to $35 \%$, suggesting that these mutations occurred early in development and likely existed in the neural tissues. Such somatic mutations likely explain the pathogenesis of certain brain malformations.

\section{Somatic mutations and psychiatric disorders: postmortem brain analyses}

Psychiatric disorders are often associated with fewer anatomical changes than brain malformations, making it relatively difficult to explore somatic mutations associated with these conditions. In one early study, one individual who had died by committing suicide exhibited a CNV specific to 
pons, although no clinical psychiatric data were presented [26]. Telomere length is generally variable in somatic cells. A characteristic reduction in telomere length has been observed in the hippocampus of patients with major depressive disorder [107].

In schizophrenia, WGS experiments by Kim et al. [108] revealed somatic deletions in BOD1, CBX3, PRKRA, MIR548N, MRPL42, SUCLG2, TDG, and another intergenic region in the prefrontal cortex, cerebellum, and white matter of three patients with schizophrenia. These somatic deletions were validated via Sanger sequencing, the lengths of which ranged from 466 to $5604 \mathrm{bp}$. Of note, similar somatic deletions of approximately $500 \mathrm{bp}$ were detected in chromosome 2 (PRKRA and MIR548N) in samples from two independent patients, indicating that this region exhibits vulnerability to mutation. Two color microarray analysis of striatal tissue samples from 48 patients revealed gene dosage loss at 1p36.21 and 1p13.3, and these results were further validated using qPCR [109]. Another study reported excess aneuploidy in postmortem brain samples from patients with schizophrenia [110]. Taken together, these findings indicate the relevance of somatic CNVs in schizophrenia.

Previously, we reported a LINE-1 copy number increase in the postmortem brains (frontal cortex) of patients with schizophrenia in two independent cohorts [89]. The copynumber increase of LINE1 was characteristic of the genomes from isolated neuronal nuclei [111], suggesting somatic retrotransposition in neurons in schizophrenia. Increased LINE-1 copy number has also been observed in animal models of schizophrenia and neurons differentiated from induced pluripotent stem cells derived from patients. Of note, LINE-1 insertions were enriched in neuronexpressed genes. Doyle et al. [112] independently confirmed these results, demonstrating increased LINE-1 insertion in genes associated with synaptic function and schizophrenia in the postmortem dorsolateral prefrontal cortex of 36 patients with schizophrenia. LINE-1 copy number increases have also been observed in the postmortem brains of patients with Rett syndrome and ataxia telangiectasia [113, 114]. However, further studies are required to determine the precise site of new insertion during somatic LINE-1 retrotransposition, and to elucidate the association between LINE-1 retrotransposition and schizophrenia.

Several somatic SNVs have been associated with ASD. Five somatic SNVs, including three somatic SNVs on $C A C$ $N A 1 C, S C N 1 A$, and SETD2, were detected in the postmortem brains of five patients with either ASD or fragile X syndrome [115]. As these genes are well-established candidate risk genes for ASD, these findings indicate that somatic mutations may be associated with the development of ASD.
The risk genes and brain regions associated with Alzheimer's disease (AD) have been relatively more elucidated than those associated with other psychiatric disorders, and several research groups have identified somatic mutations in the brains of patients with AD [116-119]. Sala Frigerio et al. [116] explored somatic mutations in the entorhinal cortex of 72 patients with $\mathrm{AD}$ and 58 healthy controls via TAS of the APP, PSEN1, PSEN2, and MAPT genes. The entorhinal cortex exhibits AD pathology in the very early stages of the disease, and APP, PSEN1, and PSEN2 are the strongest known risk genes for AD. MAPT in particular is known to involve tangle formation. The authors identified three somatic mutations in MAPT in patients with AD and PSEN2 in healthy individuals using ultra deep TAS validation, with allele fractions ranging from 0.7 to $1.6 \%$ in the entorhinal cortices. Bushman et al. [117] identified up to 12 copies of $A P P$ in the cortical genome of patients with $\mathrm{AD}$ via single-cell qPCR. They also reported that cortical nuclei from patients with $\mathrm{AD}$ exhibited an average DNA content increase of $\sim 8 \%$, relative to controls. Various groups have also observed excess aneuploidy in postmortem brain samples from patients with AD using FISH [120]. However, one single-cell WGS study reported no characteristic aneuploidy associated with $\mathrm{AD}$ [121]. In this previous study, the authors analyzed 30-130 single neurons obtained from the frontal cortex of each of the 10 patients with AD and six healthy controls. Three patients with AD exhibited aneuploidy in $1.7-2.7 \%$ of the cells, while one of the control individuals exhibited aneuploidy in $5.6 \%$ of the cells. The authors concluded the absence of strong evidence for common aneuploidy in normal and Alzheimer's disease neurons.

\section{Somatic mutations and psychiatric disorders: analyses of peripheral tissue}

Four groups have investigated somatic mutations using WES data for blood samples obtained from large cohorts of families with ASD (Simons Simplex Collection) [11, 12, 122, 123]. These WES data were originally obtained to investigate germline mutations. Lim et al. [123] added a large number of samples, analyzing WES data from $~ 6000$ families. These four groups detected several hundred somatic mutations in blood cells, including mutations of CHD2, RELN, SCN2A, SYNGAP1, and other known ASD risk genes. Seven to 22 percent of the mutations originally identified as germline de novo mutations [14, 33] were eventually discovered to be postzygotic somatic mutations. Accumulating evidence indicates that the somatic mutations detected in these blood samples contribute an estimated $3-5 \%$ to ASD diagnosis [11, 12, 122]. 
Further analyses of blood samples from families with ASD have revealed that somatic SNVs are enriched on the antisense strand, indicating that some somatic mutations are caused by transcription-coupled nucleotide excision repair [123]. In ASD, somatic SNVs are associated with an excess of deleterious mutations in critical exons of genes expressed during early brain development, especially those expressed in the prenatal amygdala [123]. Among the somatic SNVs, synonymous mutations tended to influence splicing, as implicated by computational prediction [12], and missense or loss-of-function mutations with allele fractions $>20 \%$ were more abundant in the probands than in the siblings [11]. Notably, male siblings without ASD exhibited moderate ASD-like traits if they possessed deleterious somatic mutations with a low allele fraction [11]. Furthermore, $\mathrm{C}>\mathrm{T}$ transitions were enriched in the detected somatic mutations, which Dou et al. [11] inferred were the products of $5 \mathrm{mC}$ deamination.

Rett syndrome, which is characterized by repetitive stereotyped movements and autistic features, is caused by mutations in MECP2 located on the X chromosome [124]. Rett syndrome usually occurs only in females, as a lack of functional $M E C P 2$ results in embryonic lethality. Most patients with Rett syndrome exhibit de novo germline mutations in $M E C P 2$, although some exhibit somatic mutations in MECP2 in blood cells [125]. The somatic mutations should be shared between the brain and peripheral blood cells, resulting in the characteristic symptoms of Rett syndrome. Although very rare, Rett syndrome can occur in male patients, likely due to somatic mutations in $M E C P 2$.

\section{Somatic mutations in phenotypically discordant monozygotic twins}

As monozygotic twins are assumed to have identical genomic information, any phenotypic discordance between two such siblings is classically attributed to environmental factors. However, monozygotic twins have different somatic mutation profiles, which may also account for phenotypic discordance. Several studies have reported monozygotic twins with a discordance of genetic diseases due to somatic chromosomal abnormalities or CNVs [126, 127]. Comprehensive analyses including WGS have identified several somatic SNVs in monozygotic twins without neuropsychiatric diseases [128, 129], although these studies did not associate somatic mutations with individual phenotypes.

Other research groups have identified somatic mutations in discordant monozygotic twins, with only the affected twin exhibiting somatic mutations in the relevant genes, in the following disorders: Darier disease (ATP2A2) [130],
Van der Woude syndrome (IRF6) [131], Dravet syndrome (SCN1A) [132], and neurofibromatosis type I (NF1) [133]. One study involving exome-wide investigation detected mutations in FBXO38, SMOC2, and TDRP only in the affected twin from a pair of monozygotic twins discordant for gender dysphoria [134]. A previous study also reported that monozygotic twins discordant for the severity of fragile $\mathrm{X}$ syndrome exhibited differences in CGG triplet repeat numbers [135]. Several pairs of monozygotic twins discordant for Parkinson's disease had discordant CNV profiles in blood cells [136]. In addition, we identified a missense somatic mutation in $A B C C 9$ in one twin with a delusional disorder, which was not present in the healthy cotwin [137]. A previous meta-analysis of GWAS research revealed that $A B C C 9$ is associated with sleep duration [138], indicating that somatic mutations of this gene may be associated with delusional disorders. Overall, studies of discordant monozygotic twins, particularly when combined with analyses of de novo and somatic mutations, will aid researchers in identifying risk genes for psychiatric disorders.

\section{Technical issues in psychiatric research}

Several issues must be considered during analyses of somatic mutations in human brain samples: (i) the brain region, (ii) sampling method, (iii) sequencing strategy, (iv) candidate detection, and (v) validation.

\section{(i) Selecting the brain region for analysis}

For most psychiatric disorders, the brain regions directly associated with disease etiology have yet to be identified. Therefore, there are no definitive criteria for selecting the appropriate brain regions for analysis. This is in notable contrast to the investigation of brain malformations, wherein the localization can be clearly defined. However, recent consortium-based neuroimaging studies have begun to identify the anatomical brain changes associated with psychiatric disorders at fine resolution. Large-scale MRI studies have demonstrated that significant volume reduction occurs in the hippocampus, amygdala, thalamus, and nucleus accumbens in patients with schizophrenia [139, 140]. Other studies have reported that schizophrenia is also associated with cortical thinning due to reductions in gray matter volume in regions such as the left superior temporal gyrus and left Heschl's gyrus [141, 142]. Similarly, largescale MRI studies have identified significant volume reduction in the hippocampus, thalamus, left pars opercularis, left fusiform gyrus, and left rostral middle frontal cortex in patients with bipolar disorder [143, 144]. While such changes are not always related to disease onset, 
they may be the first choice for investigating somatic mutations.

As postmortem brain tissue is not always available, peripheral tissues must be used as alternatives in many cases. Previous studies have identified causative somatic mutations in the relevant genes using peripheral tissue samples from patients with brain malformations or Rett syndrome [105, 106, 125]. Somatic mutations have also been identified in potential risk genes using blood samples from patients with ASD [11, 12, 122, 123]. The allele fraction of somatic mutations in the relevant genes ranged from 1 to $14 \%$ in the Jamuar et al. [106] study and from 1 to $43 \%$ in the Riviere et al. [105] study in peripheral tissues, indicating that these mutations likely occurred early in development and are shared between the brain and peripheral tissues. Assuming an estimated 2.8 substitution mutations per early embryonic cell per cell doubling [24], several somatic mutations occurring early in development should exist in the blood, and can be detected with high-depth sequencing. Thus, peripheral tissues may be helpful if the somatic mutations associated with the target disease occur early in development.

However, aging should be taken into account when using peripheral blood cells. Several large-scale cohort studies reported higher allele fractions and higher rates of somatic SNVs and CNVs in peripheral blood cells in older adults due to clonal expansion from hematopoiesis [145-148]. In these studies, detectable somatic mutations were in individuals aged 40 years or older but were rare in younger populations. One study involving two pairs of monozygotic twins suggested that the older pairs tended to have discordant mutations (somatic mutations), likely due to clonal expansion associated with hematopoiesis [149]. Therefore, researchers should account for clonal expansion during hematopoiesis when investigating somatic mutations in peripheral blood cells. Samples from younger individuals (under 40 years of age) are desirable to reduce the possibility of hematopoiesis-derived somatic mutations.

\section{(ii) Sampling method}

Single-cell analysis is advantageous for detection of somatic mutations that occur later in development. However, false positives are induced by deamination during cell lysis, amplification bias, and errors during WGA [48]. Each WGA method (MDA, MALBAC, or DOP-PCR) is associated with advantages and disadvantages [150], necessitating careful examination. Linear amplification via transposon insertion (LIANTI), a recently proposed WGA method, is suggested to reduce amplification bias [48]. False positives indicating $\mathrm{C}>\mathrm{T}$ due to spontaneous $\mathrm{C}>\mathrm{U}$ deamination during single-cell preparation can be reduced using uracil DNA glycosylase [48]. Somatic cell nuclear transfer (SCNT) of neuronal nuclei into enucleated oocytes has also been proposed as a method of WGA, although this method has only been applied to single neurons in mice [151]. In six mouse neurons, WGS after SCNT identified an estimated 86.2 SNVs, 22.5 insertion/deletions, 2.5 structural variants, and 1.3 mobile element insertions per neuron on an average. The authors claimed that SCNT results in fewer amplification errors than does conventional WGA, as it utilizes a natural cellular proliferation mechanism.

Analyses of bulk brain tissue are complementary to single-cell analysis, as they offer several distinct advantages; such analyses are (i) free of $\mathrm{C}>\mathrm{T}$ false positives due to $\mathrm{C}>\mathrm{U}$ deamination during cell lysis [48], (ii) free of PCR or WGA errors when using PCR-free library preparations, (iii) allow for approximate assessment of allele fractions, (iv) and are more applicable to clinically oriented research involving large sample sizes.

When a target population of cells has been defined, accurate methods of sorting or dissection would be useful. We sorted bulk brain tissue into neuronal and non-neuronal nuclei using the NeuN-based fluorescence-activated cellsorting method for analysis of LINE-1 [89], and recent studies reported methods for sorting the nuclei of oligodendrocytes [152], GABAergic interneurons, and glutamatergic neurons [153] from human postmortem brains.

\section{(iii) Sequencing strategy}

Selecting the target genomic region is among the most important issues. Although risk genes have yet to be identified for most psychiatric disorders, recent genomic studies have revealed several candidate genes as rare variants with strong effect sizes. However, if the target genes are unclear, more comprehensive methods such as WGS or WES are required. The selection of WGS, WES, or TAS depends on the research purpose as well as the target disorder. We performed sample size calculation to detect deleterious somatic mutations of early embryonic origin using WES at a depth of $300 \times$, by assuming that deleterious somatic mutations were enriched 1.8-fold in a case group, which was a ratio similar to that of germline de novo mutations reported by Iossifov et al. [14]. This resulted in a requirement of 250 samples for each group for a statistical power of 0.8 (Supplementary Note). TAS using a molecular inversion probe [154], which has been used to detect rare germline variants in large cohorts of patients with ASD [19], would be cost effective for detecting somatic as well as germline mutations.

The choice of the sequencing machines is also important. Most current somatic mutation studies have adopted the HiSeq or MiSeq machines (Illumina, San Diego, CA, USA) [155] as massively parallel sequencers for WGS, WES, or TAS. Illumina short-read technology is cost effective, but it 
is difficult to analyze regions with large homologous sequences or repeat regions, including retrotransposons with this method [156]. Target enrichment sequencing methods such as RC-Seq [65, 66] and L1Hs-Seq [70] are required to analyze repeat regions. Illumina short-read sequencing is associated with other issues as well, such as index switching [157] and systematic errors [158], requiring caution before investigating somatic mutations. New sequencing technologies involving long-read sequencing such as PacBio/Sequel (Pacific Biosciences, Menlo Park, CA, USA) [159] and MinION/PromethION (Oxford Nanopore Technology, Oxford, UK) [160] would be advantageous for investigating structural variants and retrotransposons. CNV analysis can be performed using microarrays, but low-depth WGS is more sensitive for the detection of somatic CNVs [53], and long-read sequencers are advantageous for detecting somatic structural variants including CNVs.

\section{(iv) Candidate detection}

The allele fractions of somatic mutations in neural tissue are expected to be low due to its low proliferative capacity following differentiation. This is in notable contrast to cancer, which is characterized by hyper-proliferation and is associated with somatic mutations carrying large allele fractions. Thus, a highly sensitive approach is required to detect somatic mutations in the human brain. Cibulskis et al. [161] reported the sensitivity of MuTect, a well-known somatic mutation detection tool with high sensitivity and specificity, simulating various cases of sequencing depth. For example, MuTect requires a sequence depth of $340 \times \sim$ to achieve a sensitivity of $90 \%$ when detecting somatic mutations with allele fractions of 2\%. MuTect [161], VarScan [162], and Strelka [163] (all three pacakages have update of version 2) are frequently used to detect somatic mutations associated with cancer by comparing target and control tissues. One comparison study reported that MuTect has the highest sensitivity and specificity among the devices tested [164].

Notably, false positives due to DNA damage, PCR errors, sequence errors, and alignment errors are included in reports of somatic mutations. False positives of $\mathrm{G}>\mathrm{T}$ or $\mathrm{C}>\mathrm{A}$ due to 8-oxoguanine during PCR sample preparation were abundant in human samples, especially in cancer samples [165]. Sequencing biases have also been reported using the Illumina sequencer [158]. Caution is also required during single-cell analysis due to the artificial spontaneous $\mathrm{C}>\mathrm{U}$ deamination that occurs during cell lysis [48]. Huang et al. [166] proposed a somatic mutation detection pipeline that ensures careful exclusion of probable false positives, subsequently introducing a somatic mutation detection software called MosaicHunter [167], which are designed to detect somatic mutations without the use of control tissues.

\section{(v) Validation}

The depth of sequencing is critical for reliable identification of somatic mutations. When WES data obtained from the blood samples of patients with ASD were used $[11,12,122,123]$, validation rates among the studies ranged from 50 to $90 \%$ depending on the methods and theirsensitivity. These studies were not conducted at a sufficient depth to investigate somatic mutations, as the WES data were originally acquired to investigate germline mutations.

Candidates for somatic mutation must be validated using other genetic techniques such as ddPCR, pyrosequencing, or Sanger sequencing. Among these, ddPCR is advantageous in that it allows for precise calculation of the allele fraction and exhibits highdetection sensitivity (0.001\% ) [168]. Pyrosequencing and Sanger sequencing with many clones can also be used to calculate the allele fraction, although the resolution and sensitivity are lower than those of ddPCR (pyrosequence, 5\%) [169]. However, all these techniques exhibit difficulty in detecting SNVs in repeat regions including retrotransposons due to difficulty in PCR. TAS at ultrahigh depth (e.g., 10,000× ) can be used as an alternative method of validation, as this method can detect somatic mutations with allele fractions of as low as $0.1 \%$. However, there is a potential for systematic errors when using sequencing chemistry similar to that of initial sequencing. Somatic CNVs and retrotransposons in bulk tissues can be validated using qPCR, although the resolution is limited.

\section{Conclusion}

In the present review, we discussed current genomic studies of somatic mutations in the human brain. Somatic mutations including SNVs, CNVs, and retrotransposition have been observed in the brains of humans with and without neuropsychiatric diseases. Somatic SNVs in known risk genes have been identified for several psychiatric disorders as well as brain malformations, likely contributing to disease liability. The enrichment of somatic SNVs in neuronexpressed genes indicates their relevance in neural system dysfunction. Taken together, the accumulated evidence indicates that somatic mutations may be associated with the mechanisms underlying certain psychiatric disorders, although further research is required. As few studies have demonstrated a causal relationship of somatic mutations to disease phenotypes, future studies utilizing model animals or cells are required to demonstrate the association between the development of neuropsychiatric diseases and somatic mutations. 
Acknowledgements This work was partly supported by JSPS Grantin-Aid for Scientific Research on Innovative Areas (17H05954) to KI. This work was also supported in part by the Advanced Genome Research and Bioinformatics Study to Facilitate Medical Innovation (GRIFIN) from the Japan Agency for Medical Research and Development (AMED) (16815678) to TK.

\section{Compliance with ethical standards}

Conflict of interest The authors declare that they have no conflict of interest.

Open Access This article is licensed under a Creative Commons Attribution 4.0 International License, which permits use, sharing, adaptation, distribution and reproduction in any medium or format, as long as you give appropriate credit to the original author(s) and the source, provide a link to the Creative Commons license, and indicate if changes were made. The images or other third party material in this article are included in the article's Creative Commons license, unless indicated otherwise in a credit line to the material. If material is not included in the article's Creative Commons license and your intended use is not permitted by statutory regulation or exceeds the permitted use, you will need to obtain permission directly from the copyright holder. To view a copy of this license, visit http://creativecommons. org/licenses/by/4.0/

\section{References}

1. Schizophrenia Working Group of the Psychiatric Genomics Consortium. Biological insights from 108 schizophreniaassociated genetic loci. Nature. 2014;511:421-7.

2. Pocklington AJ, Rees E, Walters JT, Han J, Kavanagh DH, Chambert KD, et al. Novel findings from CNVs implicate inhibitory and excitatory signaling complexes in schizophrenia. Neuron. 2015;86:1203-14

3. CNV and Schizophrenia Working Groups of the Psychiatric Genomics Consortium, Psychosis Endophenotypes International Consortium. Contribution of copy number variants to schizophrenia from a genome-wide study of 41,321 subjects. Nat Genet. 2017;49:27-35.

4. Kushima I, Aleksic B, Nakatochi M, Shimamura T, Shiino T, Yoshimi A, et al. High-resolution copy number variation analysis of schizophrenia in Japan. Mol Psychiatry. 2017;22: 430-40.

5. Sanders SJ, He X, Willsey AJ, Ercan-Sencicek AG, Samocha $\mathrm{KE}$, Cicek $\mathrm{AE}$, et al. Insights into autism spectrum disorder genomic architecture and biology from 71 risk loci. Neuron. 2015;87:1215-33.

6. Geschwind DH, Flint J. Genetics and genomics of psychiatric disease. Science. 2015;349:1489-94.

7. Marshall CR, Howrigan DP, Merico D, Thiruvahindrapuram B, $\mathrm{Wu} \mathrm{W}$, Greer DS, et al. Contribution of copy number variants to schizophrenia from a genome-wide study of 41,321 subjects. Nat Genet. 2017;49:27-35.

8. de la Torre-Ubieta L, Won H, Stein JL, Geschwind DH. Advancing the understanding of autism disease mechanisms through genetics. Nat Med. 2016;22:345-61.

9. Campbell IM, Yuan B, Robberecht C, Pfundt R, Szafranski P, McEntagart ME, et al. Parental somatic mosaicism is underrecognized and influences recurrence risk of genomic disorders. Am J Hum Genet. 2014;95:173-82.

10. Rahbari R, Wuster A, Lindsay SJ, Hardwick RJ, Alexandrov LB, Al Turki S, et al. Timing, rates and spectra of human germline mutation. Nat Genet. 2016;48:126-33.
11. Dou Y, Yang X, Li Z, Wang S, Zhang Z, Ye AY, et al. Postzygotic single-nucleotide mosaicisms contribute to the etiology of autism spectrum disorder and autistic traits and the origin of mutations. Hum Mutat. 2017;38:1002-13.

12. Krupp DR, Barnard RA, Duffourd Y, Evans SA, Mulqueen RM, Bernier R, et al. Exonic mosaic mutations contribute risk for autism spectrum disorder. Am J Hum Genet. 2017;101:369-90.

13. Kirov G, Pocklington AJ, Holmans P, Ivanov D, Ikeda M, Ruderfer D, et al. De novo CNV analysis implicates specific abnormalities of postsynaptic signalling complexes in the pathogenesis of schizophrenia. Mol Psychiatry. 2012;17:142-53.

14. Iossifov I, O'Roak BJ, Sanders SJ, Ronemus M, Krumm N, Levy $\mathrm{D}$, et al. The contribution of de novo coding mutations to autism spectrum disorder. Nature. 2014;515:216-21.

15. Fromer M, Pocklington AJ, Kavanagh DH, Williams HJ, Dwyer $\mathrm{S}$, Gormley $\mathrm{P}$, et al. De novo mutations in schizophrenia implicate synaptic networks. Nature. 2014;506:179-84.

16. Kataoka M, Matoba N, Sawada T, Kazuno AA, Ishiwata M, Fujii $\mathrm{K}$, et al. Exome sequencing for bipolar disorder points to roles of de novo loss-of-function and protein-altering mutations. Mol Psychiatry. 2016;21:885-93.

17. Takata A, Xu B, Ionita-Laza I, Roos JL, Gogos JA, Karayiorgou M. Loss-of-function variants in schizophrenia risk and SETD1A as a candidate susceptibility gene. Neuron. 2014;82:773-80.

18. Singh T, Kurki MI, Curtis D, Purcell SM, Crooks L, McRae J, et al. Rare loss-of-function variants in SETD1A are associated with schizophrenia and developmental disorders. Nat Neurosci. 2016;19:571-7.

19. O'Roak BJ, Vives L, Fu W, Egertson JD, Stanaway IB, Phelps IG, et al. Multiplex targeted sequencing identifies recurrently mutated genes in autism spectrum disorders. Science. 2012;338:1619-22.

20. Roberts SA, Gordenin DA. Hypermutation in human cancer genomes: footprints and mechanisms. Nat Rev Cancer. 2014;14:786-800.

21. Tonegawa S. Somatic generation of antibody diversity. Nature. 1983;302:575-81.

22. Lupski JR. Genetics. Genome mosaicism —one human, multiple genomes. Science. 2013;341:358-9.

23. O'Huallachain M, Karczewski KJ, Weissman SM, Urban AE, Snyder MP. Extensive genetic variation in somatic human tissues. Proc Natl Acad Sci USA. 2012;109:18018-23.

24. Ju YS, Martincorena I, Gerstung M, Petljak M, Alexandrov LB, Rahbari R, et al. Somatic mutations reveal asymmetric cellular dynamics in the early human embryo. Nature. 2017;543:714-8.

25. Martincorena I, Roshan A, Gerstung M, Ellis P, Van Loo P, McLaren S, et al. Tumor evolution. High burden and pervasive positive selection of somatic mutations in normal human skin. Science. 2015;348:880-6.

26. Piotrowski A, Bruder CE, Andersson R, Diaz de Stahl T, Menzel U, Sandgren J, et al. Somatic mosaicism for copy number variation in differentiated human tissues. Hum Mutat. 2008;29:1118-24.

27. Acuna-Hidalgo R, Bo T, Kwint MP, van de Vorst M, Pinelli M, Veltman JA, et al. Post-zygotic point mutations are an underrecognized source of de novo genomic variation. Am J Hum Genet. 2015;97:67-74.

28. Biesecker LG, Spinner NB. A genomic view of mosaicism and human disease. Nat Rev Genet. 2013;14:307-20.

29. Insel TR. Brain somatic mutations: the dark matter of psychiatric genetics? Mol Psychiatry. 2014;19:156-8.

30. McConnell MJ, Moran JV, Abyzov A, Akbarian S, Bae T, Cortes-Ciriano I, et al. Intersection of diverse neuronal genomes and neuropsychiatric disease: the brain somatic mosaicism network. Science. 2017;356:eaal1641 https://doi.org/10.1126/ science.aal1641. 
31. Lee JH. Somatic mutations in disorders with disrupted brain connectivity. Exp Mol Med. 2016;48:e239.

32. Poduri A, Evrony GD, Cai X, Walsh CA. Somatic mutation, genomic variation, and neurological disease. Science. 2013;341:1237758.

33. Krumm N, Turner TN, Baker C, Vives L, Mohajeri K, Witherspoon $\mathrm{K}$, et al. Excess of rare, inherited truncating mutations in autism. Nat Genet. 2015;47:582-8.

34. Weiner DJ, Wigdor EM, Ripke S, Walters RK, Kosmicki JA, Grove $\mathrm{J}$, et al. Polygenic transmission disequilibrium confirms that common and rare variation act additively to create risk for autism spectrum disorders. Nat Genet. 2017;49:978-85.

35. Jamal SM, Basran RK, Newton S, Wang Z, Milunsky JM. Novel de novo PCDH19 mutations in three unrelated females with epilepsy female restricted mental retardation syndrome. Am J Med Genet A. 2010;152A:2475-81.

36. Thiffault I, Farrow E, Smith L, Lowry J, Zellmer L, Black B, et al. PCDH19-related epileptic encephalopathy in a male mosaic for a truncating variant. Am J Med Genet A. 2016;170:1585-9.

37. Kendler KS. Twin studies of psychiatric illness: an update. Arch Gen Psychiatry. 2001;58:1005-14.

38. Kong A, Frigge ML, Masson G, Besenbacher S, Sulem P, Magnusson G, et al. Rate of de novo mutations and the importance of father's age to disease risk. Nature. 2012;488:471-5.

39. Jonsson H, Sulem P, Kehr B, Kristmundsdottir S, Zink F, Hjartarson E, et al. Parental influence on human germline de novo mutations in 1,548 trios from Iceland. Nature. 2017;549:519-22.

40. Herculano-Houzel S. The remarkable, yet not extraordinary, human brain as a scaled-up primate brain and its associated cost. Proc Natl Acad Sci USA. 2012;109(Suppl 1):10661-8.

41. Manji H, Kato T, Di Prospero NA, Ness S, Beal MF, Krams M, et al. Impaired mitochondrial function in psychiatric disorders. Nat Rev Neurosci. 2012;13:293-307.

42. Kato T. Neurobiological basis of bipolar disorder: mitochondrial dysfunction hypothesis and beyond. Schizophr Res. 2016;187:62-6.

43. Bae T, Tomasini L, Mariani J, Zhou B, Roychowdhury T, Franjic D, et al. Different mutational rates and mechanisms in human cells at pregastrulation and neurogenesis. Science. 2017;359:550-5.

44. Lodato MA, Woodworth MB, Lee S, Evrony GD, Mehta BK, Karger A, et al. Somatic mutation in single human neurons tracks developmental and transcriptional history. Science. 2015;350:94-98.

45. Lodato MA, Rodin RE, Bohrson CL, Coulter ME, Barton AR, Kwon M, et al. Aging and neurodegeneration are associated with increased mutations in single human neurons. Science. 2017;359:555-9.

46. Sorrells SF, Paredes MF, Cebrian-Silla A, Sandoval K, Qi D, Kelley KW, et al. Human hippocampal neurogenesis drops sharply in children to undetectable levels in adults. Nature. 2018;555:377-81.

47. Lynch M. Rate, molecular spectrum, and consequences of human mutation. Proc Natl Acad Sci USA. 2010;107:961-8.

48. Chen C, Xing D, Tan L, Li H, Zhou G, Huang L, et al. Singlecell whole-genome analyses by linear amplification via transposon insertion (LIANTI). Science. 2017;356:189-94.

49. King IF, Yandava CN, Mabb AM, Hsiao JS, Huang HS, Pearson $\mathrm{BL}$, et al. Topoisomerases facilitate transcription of long genes linked to autism. Nature. 2013;501:58-62.

50. Gabel HW, Kinde B, Stroud H, Gilbert CS, Harmin DA, Kastan NR, et al. Disruption of DNA-methylation-dependent long gene repression in Rett syndrome. Nature. 2015;522:89-93.

51. Zylka MJ, Simon JM, Philpot BD. Gene length matters in neurons. Neuron. 2015;86:353-5.
52. Nishioka M, Bundo M, Ueda J, Katsuoka F, Sato Y, Kuroki Y, et al. Identification of somatic mutations in postmortem human brains by whole genome sequencing and their implications for psychiatric disorders. Psychiatry Clin Neurosci. 2018;72: 280-94.

53. McConnell MJ, Lindberg MR, Brennand KJ, Piper JC, Voet T, Cowing-Zitron $\mathrm{C}$, et al. Mosaic copy number variation in human neurons. Science. 2013;342:632-7.

54. Cai X, Evrony GD, Lehmann HS, Elhosary PC, Mehta BK, Poduri A, et al. Single-cell, genome-wide sequencing identifies clonal somatic copy-number variation in the human brain. Cell Rep. 2014;8:1280-9.

55. Rehen SK, Yung YC, McCreight MP, Kaushal D, Yang AH, Almeida BS, et al. Constitutional aneuploidy in the normal human brain. J Neurosci. 2005;25:2176-80.

56. Knouse KA, Wu J, Whittaker CA, Amon A. Single cell sequencing reveals low levels of aneuploidy across mammalian tissues. Proc Natl Acad Sci USA. 2014;111:13409-14.

57. Sigl-Glockner J, Brecht M. Polyploidy and the cellular and areal diversity of rat cortical layer 5 pyramidal neurons. Cell Rep. 2017;20:2575-83.

58. Lander ES, Linton LM, Birren B, Nusbaum C, Zody MC, Baldwin $\mathrm{J}$, et al. Initial sequencing and analysis of the human genome. Nature. 2001;409:860-921.

59. Kazazian HH Jr., Moran JV. Mobile DNA in health and disease. N Engl J Med. 2017;377:361-70.

60. Kazazian HH Jr, Wong C, Youssoufian H, Scott AF, Phillips DG, Antonarakis SE. Haemophilia A resulting from de novo insertion of L1 sequences represents a novel mechanism for mutation in man. Nature. 1988;332:164-6.

61. Hancks DC, Kazazian HH Jr.. Roles for retrotransposon insertions in human disease. Mob DNA. 2016;7:9.

62. Muotri AR, Chu VT, Marchetto MC, Deng W, Moran JV, Gage FH. Somatic mosaicism in neuronal precursor cells mediated by L1 retrotransposition. Nature. 2005;435:903-10.

63. Coufal NG, Garcia-Perez JL, Peng GE, Yeo GW, Mu Y, Lovci MT, et al. L1 retrotransposition in human neural progenitor cells. Nature. 2009;460:1127-31.

64. Macia A, Widmann TJ, Heras SR, Ayllon V, Sanchez L, Benkaddour-Boumzaouad M, et al. Engineered LINE-1 retrotransposition in nondividing human neurons. Genome Res. 2017;27:335-48.

65. Baillie JK, Barnett MW, Upton KR, Gerhardt DJ, Richmond TA, De Sapio F, et al. Somatic retrotransposition alters the genetic landscape of the human brain. Nature. 2011;479: 534-7.

66. Upton KR, Gerhardt DJ, Jesuadian JS, Richardson SR, SanchezLuque FJ, Bodea GO, et al. Ubiquitous L1 mosaicism in hippocampal neurons. Cell. 2015;161:228-39.

67. Zong C, Lu S, Chapman AR, Xie XS. Genome-wide detection of single-nucleotide and copy-number variations of a single human cell. Science. 2012;338:1622-6.

68. Evrony GD, Cai X, Lee E, Hills LB, Elhosary PC, Lehmann HS, et al. Single-neuron sequencing analysis of L1 retrotransposition and somatic mutation in the human brain. Cell. 2012;151: 483-96.

69. Evrony GD, Lee E, Mehta BK, Benjamini Y, Johnson RM, Cai $\mathrm{X}$, et al. Cell lineage analysis in human brain using endogenous retroelements. Neuron. 2015;85:49-59.

70. Ewing AD, Kazazian HH Jr. High-throughput sequencing reveals extensive variation in human-specific L1 content in individual human genomes. Genome Res. 2010;20: 1262-70.

71. Evrony GD, Lee E, Park PJ, Walsh CA. Resolving rates of mutation in the brain using single-neuron genomics. Elife. 2016;5:e12966 https://doi.org/10.7554/eLife.12966. 
72. Kriaucionis S, Heintz N. The nuclear DNA base 5hydroxymethylcytosine is present in Purkinje neurons and the brain. Science. 2009;324:929-30.

73. Lister R, Mukamel EA, Nery JR, Urich M, Puddifoot CA, Johnson ND, et al. Global epigenomic reconfiguration during mammalian brain development. Science. 2013;341: 1237905.

74. Cortellino S, Xu J, Sannai M, Moore R, Caretti E, Cigliano A, et al. Thymine DNA glycosylase is essential for active DNA demethylation by linked deamination-base excision repair. Cell. 2011;146:67-79.

75. Guo JU, Su Y, Zhong C, Ming GL, Song H. Hydroxylation of 5methylcytosine by TET1 promotes active DNA demethylation in the adult brain. Cell. 2011;145:423-34.

76. Kohli RM, Zhang Y. TET enzymes, TDG and the dynamics of DNA demethylation. Nature. 2013;502:472-9.

77. Tomkova M, McClellan M, Kriaucionis S, Schuster-Boeckler B. 5-hydroxymethylcytosine marks regions with reduced mutation frequency in human DNA. eLife. 2016;5:5-hydroxymethylcytosine marks regions with reduced mutation frequency in human DNA. eLife. 2016;5:e17082.

78. Morgan HD, Dean W, Coker HA, Reik W, Petersen-Mahrt SK. Activation-induced cytidine deaminase deaminates 5methylcytosine in DNA and is expressed in pluripotent tissues: implications for epigenetic reprogramming. J Biol Chem. 2004;279:52353-60.

79. Nabel CS, Jia H, Ye Y, Shen L, Goldschmidt HL, Stivers JT, et al. AID/APOBEC deaminases disfavor modified cytosines implicated in DNA demethylation. Nat Chem Biol. 2012;8:751-8.

80. Suberbielle E, Sanchez PE, Kravitz AV, Wang X, Ho K, Eilertson K, et al. Physiologic brain activity causes DNA doublestrand breaks in neurons, with exacerbation by amyloid-beta. Nat Neurosci. 2013;16:613-21.

81. Madabhushi R, Gao F, Pfenning AR, Pan L, Yamakawa S, Seo J, et al. Activity-induced DNA breaks govern the expression of neuronal early-response genes. Cell. 2015;161:1592-605.

82. Wei PC, Chang AN, Kao J, Du Z, Meyers RM, Alt FW, et al. Long neural genes harbor recurrent DNA break clusters in neural stem/progenitor cells. Cell. 2016;164:644-55.

83. McKinnon PJ. Maintaining genome stability in the nervous system. Nat Neurosci. 2013;16:1523-9.

84. Cooke MS, Evans MD, Dizdaroglu M, Lunec J. Oxidative DNA damage: mechanisms, mutation, and disease. FASEB J. 2003;17:1195-214.

85. Lu T, Pan Y, Kao SY, Li C, Kohane I, Chan J, et al. Gene regulation and DNA damage in the ageing human brain. Nature. 2004;429:883-91.

86. Lin MT, Beal MF. Mitochondrial dysfunction and oxidative stress in neurodegenerative diseases. Nature. 2006;443:787-95.

87. Mecocci P, MacGarvey U, Kaufman AE, Koontz D, Shoffner $\mathrm{JM}$, Wallace DC, et al. Oxidative damage to mitochondrial DNA shows marked age-dependent increases in human brain. Ann Neurol. 1993;34:609-16.

88. Sheng Z, Oka S, Tsuchimoto D, Abolhassani N, Nomaru H, Sakumi K, et al. 8-Oxoguanine causes neurodegeneration during MUTYH-mediated DNA base excision repair. J Clin Invest. 2012;122:4344-61.

89. Bundo M, Toyoshima M, Okada Y, Akamatsu W, Ueda J, Nemoto-Miyauchi T, et al. Increased 11 retrotransposition in the neuronal genome in schizophrenia. Neuron. 2014;81:306-13.

90. Erwin JA, Paquola AC, Singer T, Gallina I, Novotny M, Quayle $\mathrm{C}$, et al. L1-associated genomic regions are deleted in somatic cells of the healthy human brain. Nat Neurosci. 2016;19: 1583-91.
91. Shibata Y, Kumar P, Layer R, Willcox S, Gagan JR, Griffith JD, et al. Extrachromosomal microDNAs and chromosomal microdeletions in normal tissues. Science. 2012;336:82-86.

92. Lee JH, Huynh M, Silhavy JL, Kim S, Dixon-Salazar T, Heiberg A, et al. De novo somatic mutations in components of the PI3KAKT3-mTOR pathway cause hemimegalencephaly. Nat Genet. 2012;44:941-5.

93. D'Gama AM, Geng Y, Couto JA, Martin B, Boyle EA, LaCoursiere CM, et al. Mammalian target of rapamycin pathway mutations cause hemimegalencephaly and focal cortical dysplasia. Ann Neurol. 2015;77:720-5.

94. Jansen LA, Mirzaa GM, Ishak GE, O'Roak BJ, Hiatt JB, Roden $\mathrm{WH}$, et al. PI3K/AKT pathway mutations cause a spectrum of brain malformations from megalencephaly to focal cortical dysplasia. Brain. 2015;138(Pt 6):1613-28.

95. Poduri A, Evrony GD, Cai X, Elhosary PC, Beroukhim R, Lehtinen MK, et al. Somatic activation of AKT3 causes hemispheric developmental brain malformations. Neuron. 2012;74:41-48.

96. Mirzaa GM, Campbell CD, Solovieff N, Goold CP, Jansen LA, Menon S, et al. Association of MTOR mutations with developmental brain disorders, including megalencephaly, focal cortical dysplasia, and pigmentary mosaicism. JAMA Neurol. 2016;73:836-45.

97. Lim JS, Kim WI, Kang HC, Kim SH, Park AH, Park EK, et al. Brain somatic mutations in MTOR cause focal cortical dysplasia type II leading to intractable epilepsy. Nat Med. 2015;21:395-400.

98. Nakashima M, Saitsu H, Takei N, Tohyama J, Kato M, Kitaura $\mathrm{H}$, et al. Somatic mutations in the MTOR gene cause focal cortical dysplasia type IIb. Ann Neurol. 2015;78:375-86.

99. Shirley MD, Tang H, Gallione CJ, Baugher JD, Frelin LP, Cohen $\mathrm{B}$, et al. Sturge-Weber syndrome and port-wine stains caused by somatic mutation in GNAQ. N Engl J Med. 2013;368:1971-9.

100. Nakashima M, Miyajima M, Sugano H, Iimura $Y$, Kato $M$, Tsurusaki Y, et al. The somatic GNAQ mutation c.548G>A (p. $\mathrm{R} 183 \mathrm{Q}$ ) is consistently found in Sturge-Weber syndrome. J Hum Genet. 2014;59:691-3.

101. Gatchel JR, Zoghbi HY. Diseases of unstable repeat expansion: mechanisms and common principles. Nat Rev Genet. 2005;6:743-55

102. McMurray CT. Mechanisms of trinucleotide repeat instability during human development. Nat Rev Genet. 2010;11:786-99.

103. Kennedy L, Evans E, Chen CM, Craven L, Detloff PJ, Ennis M, et al. Dramatic tissue-specific mutation length increases are an early molecular event in Huntington disease pathogenesis. Hum Mol Genet. 2003;12:3359-67.

104. Swami M, Hendricks AE, Gillis T, Massood T, Mysore J, Myers $\mathrm{RH}$, et al. Somatic expansion of the Huntington's disease CAG repeat in the brain is associated with an earlier age of disease onset. Hum Mol Genet. 2009;18:3039-47.

105. Riviere JB, Mirzaa GM, O'Roak BJ, Beddaoui M, Alcantara D, Conway RL, et al. De novo germline and postzygotic mutations in AKT3, PIK3R2 and PIK3CA cause a spectrum of related megalencephaly syndromes. Nat Genet. 2012;44:934-40.

106. Jamuar SS, Lam AT, Kircher M, D’Gama AM, Wang J, Barry BJ, et al. Somatic mutations in cerebral cortical malformations. N Engl J Med. 2014;371:733-43.

107. Mamdani F, Rollins B, Morgan L, Myers RM, Barchas JD, Schatzberg AF, et al. Variable telomere length across postmortem human brain regions and specific reduction in the hippocampus of major depressive disorder. Transl Psychiatry. 2015;5:e636.

108. Kim J, Shin JY, Kim JI, Seo JS, Webster MJ, Lee D, et al. Somatic deletions implicated in functional diversity of brain cells 
of individuals with schizophrenia and unaffected controls. Sci Rep. 2014;4:3807.

109. Sakai M, Watanabe Y, Someya T, Araki K, Shibuya M, Niizato $\mathrm{K}$, et al. Assessment of copy number variations in the brain genome of schizophrenia patients. Mol Cytogenet. 2015; $8: 46$.

110. Yurov YB, Iourov IY, Vorsanova SG, Demidova IA, Kravetz VS, Beresheva AK, et al. The schizophrenia brain exhibits lowlevel aneuploidy involving chromosome 1. Schizophr Res. 2008;98:139-47.

111. Iwamoto K, Bundo M, Ueda J, Oldham MC, Ukai W, Hashimoto E, et al. Neurons show distinctive DNA methylation profile and higher interindividual variations compared with non-neurons. Genome Res. 2011;21:688-96.

112. Doyle GA, Crist RC, Karatas ET, Hammond MJ, Ewing AD, Ferraro TN, et al. Analysis of LINE-1 elements in dna from postmortem brains of individuals with schizophrenia. Neuropsychopharmacology. 2017;42:2602-11.

113. Coufal NG, Garcia-Perez JL, Peng GE, Marchetto MC, Muotri $\mathrm{AR}, \mathrm{Mu} \mathrm{Y}$, et al. Ataxia telangiectasia mutated (ATM) modulates long interspersed element-1 (L1) retrotransposition in human neural stem cells. Proc Natl Acad Sci USA. 2011;108:20382-7.

114. Muotri AR, Marchetto MC, Coufal NG, Oefner R, Yeo G, Nakashima K, et al. L1 retrotransposition in neurons is modulated by MeCP2. Nature. 2010;468:443-6.

115. D'Gama AM, Pochareddy S, Li M, Jamuar SS, Reiff RE, Lam AT, et al. Targeted DNA sequencing from autism spectrum disorder brains implicates multiple genetic mechanisms. Neuron. 2015;88:910-7.

116. Sala Frigerio C, Lau P, Troakes C, Deramecourt V, Gele P, Van Loo $\mathrm{P}$, et al. On the identification of low allele frequency mosaic mutations in the brains of Alzheimer's disease patients. Alzheimers Dement. 2015;11:1265-76.

117. Bushman DM, Kaeser GE, Siddoway B, Westra JW, Rivera RR, Rehen SK, et al. Genomic mosaicism with increased amyloid precursor protein (APP) gene copy number in single neurons from sporadic Alzheimer's disease brains. Elife. 2015;4:e05116 https://doi.org/10.7554/eLife.05116.

118. Beck JA, Poulter M, Campbell TA, Uphill JB, Adamson G, Geddes JF, et al. Somatic and germline mosaicism in sporadic early-onset Alzheimer's disease. Hum Mol Genet. 2004;13:1219-24.

119. Parcerisas A, Rubio SE, Muhaisen A, Gomez-Ramos A, Pujadas L, Puiggros M, et al. Somatic signature of brain-specific single nucleotide variations in sporadic Alzheimer's disease. J Alzheimers Dis. 2014;42:1357-82.

120. Bajic V, Spremo-Potparevic B, Zivkovic L, Isenovic ER, Arendt T. Cohesion and the aneuploid phenotype in Alzheimer's disease: a tale of genome instability. Neurosci Biobehav Rev. 2015;55:365-74.

121. van den Bos H, Spierings DC, Taudt AS, Bakker B, Porubsky D, Falconer E, et al. Single-cell whole genome sequencing reveals no evidence for common aneuploidy in normal and Alzheimer's disease neurons. Genome Biol. 2016;17:116.

122. Freed D, Pevsner J. The contribution of mosaic variants to autism spectrum disorder. PLoS Genet. 2016;12:e1006245.

123. Lim ET, Uddin M, De Rubeis S, Chan Y, Kamumbu AS, Zhang $\mathrm{X}$, et al. Rates, distribution and implications of postzygotic mosaic mutations in autism spectrum disorder. Nat Neurosci. 2017;20:1217-24.

124. Amir RE, Van den Veyver IB, Wan M, Tran CQ, Francke U, Zoghbi HY. Rett syndrome is caused by mutations in X-linked MECP2, encoding methyl-CpG-binding protein 2. Nat Genet. 1999;23:185-8.
125. Clayton-Smith J, Watson P, Ramsden S, Black GC. Somatic mutation in MECP2 as a non-fatal neurodevelopmental disorder in males. Lancet. 2000;356:830-2.

126. Machin GA. Some causes of genotypic and phenotypic discordance in monozygotic twin pairs. Am J Med Genet. 1996;61:216-28.

127. Kato T, Iwamoto K, Kakiuchi C, Kuratomi G, Okazaki Y. Genetic or epigenetic difference causing discordance between monozygotic twins as a clue to molecular basis of mental disorders. Mol Psychiatry. 2005;10:622-30.

128. Dal GM, Erguner B, Sagiroglu MS, Yuksel B, Onat OE, Alkan $\mathrm{C}$, et al. Early postzygotic mutations contribute to de novo variation in a healthy monozygotic twin pair. J Med Genet. 2014;51:455-9.

129. Li R, Montpetit A, Rousseau M, Wu SY, Greenwood CM, Spector TD, et al. Somatic point mutations occurring early in development: a monozygotic twin study. J Med Genet. 2014;51:28-34.

130. Sakuntabhai A, Ruiz-Perez V, Carter S, Jacobsen N, Burge S, Monk S, et al. Mutations in ATP2A2, encoding a Ca2+ pump, cause Darier disease. Nat Genet. 1999;21:271-7.

131. Kondo S, Schutte BC, Richardson RJ, Bjork BC, Knight AS, Watanabe Y, et al. Mutations in IRF6 cause Van der Woude and popliteal pterygium syndromes. Nat Genet. 2002;32:285-9.

132. Vadlamudi L, Dibbens LM, Lawrence KM, Iona X, McMahon $\mathrm{JM}$, Murrell W, et al. Timing of de novo mutagenesis--a twin study of sodium-channel mutations. $\mathrm{N}$ Engl $\mathrm{J}$ Med. 2010;363:1335-40.

133. Vogt J, Kohlhase J, Morlot S, Kluwe L, Mautner VF, Cooper DN, et al. Monozygotic twins discordant for neurofibromatosis type 1 due to a postzygotic NF1 gene mutation. Hum Mutat. 2011;32:E2134-2147.

134. Morimoto Y, Ono S, Imamura A, Okazaki Y, Kinoshita A, Mishima $\mathrm{H}$, et al. Deep sequencing reveals variations in somatic cell mosaic mutations between monozygotic twins with discordant psychiatric disease. Hum Genome Var. 2017;4:17032.

135. Helderman-van den Enden AT, Maswinkel-Mooij PD, Hoogendoorn E, Willemsen R, Maat-Kievit JA, Losekoot M, et al. Monozygotic twin brothers with the fragile $\mathrm{X}$ syndrome: different CGG repeats and different mental capacities. J Med Genet. 1999;36:253-7.

136. Bruder CE, Piotrowski A, Gijsbers AA, Andersson R, Erickson S, Diaz de Stahl T, et al. Phenotypically concordant and discordant monozygotic twins display different DNA copy-numbervariation profiles. Am J Hum Genet. 2008;82:763-71.

137. Nishioka M, Bundo M, Ueda J, Yoshikawa A, Nishimura F, Sasaki T, et al. Identification of somatic mutations in monozygotic twins discordant for psychiatric disorders. NPJ Schizophr. 2018;4:7.

138. Allebrandt KV, Amin N, Muller-Myhsok B, Esko T, TederLaving M, Azevedo RV, et al. A K(ATP) channel gene effect on sleep duration: from genome-wide association studies to function in Drosophila. Mol Psychiatry. 2013;18:122-32.

139. Okada N, Fukunaga M, Yamashita F, Koshiyama D, Yamamori $\mathrm{H}$, Ohi $\mathrm{K}$, et al. Abnormal asymmetries in subcortical brain volume in schizophrenia. Mol Psychiatry. 2016;21:1460-6.

140. van Erp TG, Hibar DP, Rasmussen JM, Glahn DC, Pearlson GD, Andreassen OA, et al. Subcortical brain volume abnormalities in 2028 individuals with schizophrenia and 2540 healthy controls via the ENIGMA consortium. Mol Psychiatry. 2016;21:547-53.

141. Kasai K, Shenton ME, Salisbury DF, Hirayasu Y, Lee CU, Ciszewski AA, et al. Progressive decrease of left superior temporal gyrus gray matter volume in patients with first-episode schizophrenia. Am J Psychiatry. 2003;160:156-64.

142. Kasai K, Shenton ME, Salisbury DF, Hirayasu Y, Onitsuka T, Spencer MH, et al. Progressive decrease of left Heschl gyrus and 
planum temporale gray matter volume in first-episode schizophrenia: a longitudinal magnetic resonance imaging study. Arch Gen Psychiatry. 2003;60:766-75.

143. Hibar DP, Westlye LT, van Erp TG, Rasmussen J, Leonardo CD, Faskowitz J, et al. Subcortical volumetric abnormalities in bipolar disorder. Mol Psychiatry. 2016;21:1710-6.

144. Hibar DP, Westlye LT, Doan NT, Jahanshad N, Cheung JW, Ching CRK, et al. Cortical abnormalities in bipolar disorder: an MRI analysis of 6503 individuals from the ENIGMA Bipolar Disorder Working Group. Mol Psychiatry. 2017;23:932-42.

145. Genovese G, Kahler AK, Handsaker RE, Lindberg J, Rose SA, Bakhoum SF, et al. Clonal hematopoiesis and blood-cancer risk inferred from blood DNA sequence. $\mathrm{N}$ Engl $\mathrm{J}$ Med. 2014;371:2477-87.

146. Jaiswal S, Fontanillas P, Flannick J, Manning A, Grauman PV, Mar BG, et al. Age-related clonal hematopoiesis associated with adverse outcomes. N Engl J Med. 2014;371:2488-98.

147. Laurie CC, Laurie CA, Rice K, Doheny KF, Zelnick LR, McHugh CP, et al. Detectable clonal mosaicism from birth to old age and its relationship to cancer. Nat Genet. 2012;44:642-50.

148. Jacobs KB, Yeager M, Zhou W, Wacholder S, Wang Z, Rodriguez-Santiago B, et al. Detectable clonal mosaicism and its relationship to aging and cancer. Nat Genet. 2012;44:651-8.

149. Ye K, Beekman M, Lameijer EW, Zhang Y, Moed MH, van den Akker EB, et al. Aging as accelerated accumulation of somatic variants: whole-genome sequencing of centenarian and middleaged monozygotic twin pairs. Twin Res Hum Genet. 2013;16:1026-32.

150. Hou Y, Wu K, Shi X, Li F, Song L, Wu H, et al. Comparison of variations detection between whole-genome amplification methods used in single-cell resequencing. Gigascience. 2015;4:37.

151. Hazen JL, Faust GG, Rodriguez AR, Ferguson WC, Shumilina $\mathrm{S}$, Clark RA, et al. The complete genome sequences, unique mutational spectra, and developmental potency of adult neurons revealed by cloning. Neuron. 2016;89:1223-36.

152. Hayashi Y, Nihonmatsu-Kikuchi N, Yu X, Ishimoto K, Hisanaga SI, Tatebayashi Y. A novel, rapid, quantitative cell-counting method reveals oligodendroglial reduction in the frontopolar cortex in major depressive disorder. Mol Psychiatry. 2011;16:1155-8.

153. Kozlenkov A, Wang M, Roussos P, Rudchenko S, Barbu M, Bibikova M, et al. Substantial DNA methylation differences between two major neuronal subtypes in human brain. Nucleic Acids Res. 2016;44:2593-612.

154. Hiatt JB, Pritchard CC, Salipante SJ, O'Roak BJ, Shendure J. Single molecule molecular inversion probes for targeted, highaccuracy detection of low-frequency variation. Genome Res. 2013;23:843-54.

155. Bentley DR, Balasubramanian S, Swerdlow HP, Smith GP, Milton J, Brown CG, et al. Accurate whole human genome sequencing using reversible terminator chemistry. Nature. $2008 ; 456: 53-59$.
156. Treangen TJ, Salzberg SL. Repetitive DNA and next-generation sequencing: computational challenges and solutions. Nat Rev Genet. 2011;13:36-46.

157. Sinha R, Stanley G, Gulati GS, Ezran C, Travaglini KJ, Wei E, et al. Index switching causes "Spreading-Of-Signal" among multiplexed samples in illumina HiSeq 4000 DNA sequencing. bioRxiv. 2017 https://doi.org/10.1101/125724.

158. Nakamura K, Oshima T, Morimoto T, Ikeda S, Yoshikawa H, Shiwa Y, et al. Sequence-specific error profile of Illumina sequencers. Nucleic Acids Res. 2011;39:e90.

159. Rhoads A, Au KF. PacBio sequencing and its applications. Genom Proteom Bioinformatics. 2015;13:278-89.

160. Lu H, Giordano F, Ning Z. Oxford nanopore MinION sequencing and genome assembly. Genom Proteom Bioinformatics. 2016;14:265-79.

161. Cibulskis K, Lawrence MS, Carter SL, Sivachenko A, Jaffe D, Sougnez C, et al. Sensitive detection of somatic point mutations in impure and heterogeneous cancer samples. Nat Biotechnol. 2013:31:213-9.

162. Koboldt DC, Zhang Q, Larson DE, Shen D, McLellan MD, Lin L, et al. VarScan 2: somatic mutation and copy number alteration discovery in cancer by exome sequencing. Genome Res. 2012;22:568-76

163. Saunders CT, Wong WS, Swamy S, Becq J, Murray LJ, Cheetham RK. Strelka: accurate somatic small-variant calling from sequenced tumor-normal sample pairs. Bioinformatics. 2012;28:1811-7.

164. Xu H, DiCarlo J, Satya RV, Peng Q, Wang Y. Comparison of somatic mutation calling methods in amplicon and whole exome sequence data. BMC Genom. 2014;15:244.

165. Chen L, Liu P, Evans TC Jr, Ettwiller LM. DNA damage is a pervasive cause of sequencing errors, directly confounding variant identification. Science. 2017;355:752-6.

166. Huang AY, Xu X, Ye AY, Wu Q, Yan L, Zhao B, et al. Postzygotic single-nucleotide mosaicisms in whole-genome sequences of clinically unremarkable individuals. Cell Res. 2014;24:1311-27.

167. Huang AY, Zhang Z, Ye AY, Dou Y, Yan L, Yang X, et al. MosaicHunter: accurate detection of postzygotic singlenucleotide mosaicism through next-generation sequencing of unpaired, trio, and paired samples. Nucleic Acids Res. 2017;45: e76.

168. Hindson BJ, Ness KD, Masquelier DA, Belgrader P, Heredia NJ, Makarewicz AJ, et al. High-throughput droplet digital PCR system for absolute quantitation of DNA copy number. Anal Chem. 2011;83:8604-10.

169. Tsiatis AC, Norris-Kirby A, Rich RG, Hafez MJ, Gocke CD, Eshleman JR, et al. Comparison of Sanger sequencing, pyrosequencing, and melting curve analysis for the detection of KRAS mutations: diagnostic and clinical implications. J Mol Diagn. 2010;12:425-32. 